\title{
Dendritic Low-Threshold Calcium Currents in Thalamic Relay Cells
}

\author{
Alain Destexhe, ${ }^{1}$ Mike Neubig, ${ }^{1}$ Daniel Ulrich, ${ }^{2}$ and John Huguenard ${ }^{2}$ \\ ${ }^{1}$ Laboratoire de Neurophysiologie, Faculté de Médecine, Université Laval, Quebec G1K 7P4, Canada, and ${ }^{2}$ Department \\ of Neurology and Neurological Sciences, Stanford University Medical Center, Stanford, California 94305
}

The low-threshold calcium current $\left(I_{\mathrm{T}}\right)$ underlies burst generation in thalamocortical (TC) relay cells and plays a central role in the genesis of synchronized oscillations by thalamic circuits. Here we have combined in vitro recordings and computational modeling techniques to investigate the consequences of dendritically located $I_{\mathrm{T}}$ in TC cells. Simulations of a reconstructed TC cell were compared with the recordings obtained in the same cell to constrain the values of its passive parameters. T-current densities in soma and proximal dendrites were then estimated by matching the model to voltage-clamp recordings obtained in dissociated TC cells, which lack most of the dendrites. The distal dendritic T-current density was constrained by recordings in intact TC cells, which show 5-14 times larger peak T-current amplitudes compared with dissociated cells. Comparison of the model with the recordings of the same cell

Thalamocortical (TC) relay neurons play an essential role in the genesis of synchronized oscillations in the thalamus and in the thalamocortical system. This role is conveyed through their intrinsic ability to generate bursts of action potentials in rebound to inhibition. The importance of the rebound response of TC cells was first established by Andersen and Eccles (1962), who referred it as "post-anodal exhaltation." It was later characterized by in vivo (Deschênes et al., 1984) and in vitro intracellular recordings (Jahnsen and Llinás, 1984a) and subsequently called the "lowthreshold spike" (LTS). It was also demonstrated that a lowthreshold calcium current $\left(I_{\mathrm{T}}\right)$ underlies LTS genesis in TC cells (Jahnsen and Llinás, 1984b).

Computational models of TC cells were designed in the early work of Andersen and Rutjord (1964), who represented the rebound response of these cells by a qualitative model. Later, the biophysical characterization of the T-current by voltage-clamp methods (Coulter et al., 1989; Huguenard and Prince, 1992) provided precise data to build more detailed models. Like the model introduced by Hodgkin and Huxley (1952) for action potentials, the activation and inactivation properties of the T-current are sufficient to predict rebound burst generation in current clamp, as found by a number of modeling investigators (for review, see Destexhe and Sejnowski, 1997).

Rebound bursts play an essential role at the network level.

\footnotetext{
Received Dec. 9, 1997; revised Feb. 26, 1998; accepted March 5, 1998.

This research was supported by the Medical Research Council of Canada Grant MT-13724 and National Institute of Neurological Disorders and Stroke Grants NS-06477 and NS-34774. We thank Dr. D. Amaral for kindly allowing us to use his tracing system.

Simulation programs relative to this article can be obtained from the Internet at http://www.neuron.yale.edu/neuron.html or http://cns.fmed.ulaval.ca

Correspondence should be addressed to Dr. Alain Destexhe, Laboratoire de Neurophysiologie, Faculté de Médecine, Université Laval, Quebec G1K 7P4, Canada. Copyright (C) 1998 Society for Neuroscience $0270-6474 / 98 / 183574-15 \$ 05.00 / 0$
}

constrained further the T-current density in dendrites, which had to be 4.5-7.6 times higher than in the soma to reproduce all experimental results. Similar conclusions were reached using a simplified three-compartment model. Functionally, the model shows that the same amount of T-channels can lead to different bursting behaviors if they are exclusively somatic or distributed throughout the dendrites. In conclusion, this combination of models and experiments shows that dendritic T-currents are necessary to reproduce low-threshold calcium electrogenesis in TC cells. Dendritic T-current may also have significant functional consequences, such as an efficient modulation of thalamic burst discharges by corticothalamic feedback.

Key words: computational models; voltage clamp; bursting; oscillations; low-threshold spikes; dendritic calcium currents

Andersen and Eccles (1962) initially hypothesized that TC cells are connected reciprocally with local circuit interneurons, making a powerful oscillator through the interplay of inhibition and rebound response. Although the details were incorrect, the principle was essentially right, as shown by in vivo (Steriade et al., 1985, 1990) and slice experiments (von Krosigk et al., 1993; Huguenard and Prince, 1992), which demonstrated that oscillations are generated by the interaction between TC cells and thalamic reticular (RE) neurons. Computational models of thalamic circuits (Destexhe et al., 1993, 1996a; Wang et al., 1995; Golomb et al., 1996; for review, see Destexhe and Sejnowski, 1997) explored oscillatory mechanisms based on an interplay of inhibition and rebound burst. Possible consequences of this mechanism in synchronizing thalamocortical networks were modeled recently (Destexhe et al., 1998).

Interactions involving $\mathrm{T}$-channels may also take place at the subcellular level. A previous study on RE cells suggested evidence for high T-current densities in distal dendrites (Destexhe et al., 1996b). This study showed that dendritic T-current may explain critical electrophysiological features, such as differences in the intrinsic firing properties between RE cells recorded in vivo and in vitro. For TC cells, evidence for dendritic $I_{\mathrm{T}}$ was obtained recently from calcium imaging of proximal dendrites (Munsch et al., 1997; Zhou et al., 1997). Given the considerable number of synaptic terminals that contact the dendrites of TC cells (Jones, 1985; Liu et al., 1995), these data suggest that complex interactions between synaptic inputs and burst generation may take place in the dendrites of TC cells.

To investigate these type of interactions, we have designed a computational model of the dendritic T-current in TC cells based on a combination of in vitro recordings and computational modeling techniques. 


\section{MATERIALS AND METHODS}

In vitro recordings. The present study focuses on neurons from the ventrobasal nucleus of the thalamus of rats. All in vitro recordings were obtained in TC neurons from the ventrobasal nucleus of young rats [postnatal day 8 (P8)-P15], using either intact slice preparation or acutely dissociated TC cells. All current-clamp recordings were at a temperature of $34-36^{\circ} \mathrm{C}$, whereas voltage-clamp recordings were done at $24^{\circ} \mathrm{C}$. The methods were described in detail by Huguenard and Prince (1992).

The following procedure was used for calcium current recording in intact neurons in slices (modified from the procedure of Ulrich and Huguenard, 1995). Brain slices $(200 \mu \mathrm{m})$ were transferred into a recording chamber and superfused $(2 \mathrm{ml} / \mathrm{min}$ at room temperature) with standard artificial CSF containing (in mM): $126 \mathrm{NaCl}, 26 \mathrm{NaHCO}_{3}, 2.5$ $\mathrm{KCl}, 1.25 \mathrm{NaH}_{2} \mathrm{PO}_{4}, 2 \mathrm{MgCl}_{2}, 2 \mathrm{CaCl}_{2}, 0.001$ tetrodotoxin, and 10 glucose, equilibrated with $95 \% \mathrm{O}_{2}$ and $5 \% \mathrm{CO}_{2}$. Patch pipettes were pulled from borosilicate glass (Garner Glass, Claremont, CA) and filled with a solution containing (in $\mathrm{mM}$ ): $120 \mathrm{Cs}$ gluconate, $11 \mathrm{CsCl}, 1 \mathrm{MgCl}_{2}$, $1 \mathrm{CaCl}_{2}, 10 \mathrm{HEPES}$, and 11 EGTA, $\mathrm{pH}$ adjusted to 7.3 with $\mathrm{CsOH}$, osmolality $290 \mathrm{mOsm}$. Whole-cell recordings were made with a List EPC-7 amplifier. Series resistance was in the range of 2.5-12 M $\Omega$ and was electronically compensated by $70 \%$.

Morphology. A TC neuron was recorded in intact slice preparation and stained with biocytin. The cell is shown in Figure $1 A$ (also see Huguenard and Prince, 1992). We reconstructed the morphology of that cell from serial sections of $80 \mu \mathrm{m}$, using a computerized tracing system (Eutectic Electronics, Raleigh, NC) kindly provided by Prof. D. Amaral (University of California, Davis, CA). With the $100 \times$ objective used and correction for tissue shrinkage, the theoretical accuracy with which dendritic diameters can be measured was $0.1 \mu \mathrm{m}$. However, because of biocytin artifacts, the diameters of some distal dendrites could not be traced precisely, although lengths and branching patterns were accurately reconstructed. In those cases, the diameters were artificially rescaled to match the diameter profile of dendritic segments that could be reconstructed accurately. This procedure led to diameter profiles consistent with previous morphological studies of rat ventrobasal TC cells (Ohara and Havton, 1994). The reconstructed TC neuron is shown in Figure $1 B$.

The reconstructed morphology of the TC cell was incorporated into NEURON, which can simulate the cable geometry from the threedimensional coordinates provided by the tracing of the neuron (for more details, see Hines and Carnevale, 1997). The two equivalent cable models studied had either 208 or 1214 compartments and gave nearly identical results.

Computational models of dissociated cells. In acutely dissociated TC cells, most of the dendritic arborizations were removed by the dissociation procedure (Fig. 2A1) (also see Huguenard and Prince, 1992). Simulations of acutely dissociated TC cells used a cable geometry obtained by truncating the dendrites of the original cell (Fig. 2B1). The model shown in Figure $2 B 1$ was obtained by keeping the soma and proximal bits of dendrites of the reconstructed cell based on the morphology of dissociated TC cells (Fig. 2B2) (also see Huguenard and Prince, 1992) and the ratio of input capacitance measured experimentally $(113 \mathrm{pF}$ for the intact cell and $16.7 \mathrm{pF}$ on average for dissociated TC cells; Huguenard and Prince, 1992), leading to an area of $\sim 3500 \mu \mathrm{m}^{2}$. Distal dendrites were removed from the reconstructed cell until the model matched this area, leading to a dissociated cell model, which had only the soma and two proximal dendritic branches, with a total membrane area of $3430 \mu \mathrm{m}^{2}$ (Fig. 2B1).

Voltage-dependent currents. Voltage-dependent conductances were modeled using a Hodgkin-Huxley type of kinetic model (Hodgkin and Huxley, 1952). Because no data exist to constrain the localization and kinetics of the $\mathrm{Na}^{+}$and $\mathrm{K}^{+}$currents responsible for fast action potentials, they were inserted in the soma, and their kinetics were taken from a model of hippocampal pyramidal cells (Traub and Miles, 1991), assuming a resting potential of $V_{\mathrm{T}}=-52 \mathrm{mV}$ in their equations, maximal conductances of $\bar{g}_{\mathrm{Na}}=100 \mathrm{mS} / \mathrm{cm}^{2}$ and $\bar{g}_{\mathrm{K}}=100 \mathrm{mS} / \mathrm{cm}^{2}$, and reversal potentials of $E_{\mathrm{Na}}=50 \mathrm{mV}$ and $E_{\mathrm{K}}=-100 \mathrm{mV}$. This model was already shown to be adequate to model the repetitive firing within bursts of action potentials (Traub and Miles, 1991; Destexhe et al., 1996a,b).

The kinetics of activation and inactivation of $I_{\mathrm{T}}$ in TC cells were modified from a previous model (Huguenard and McCormick, 1992). The activation functions were empirically corrected to account for both voltage-clamp and current-clamp data on TC cells, assuming a $\pm 3 \mathrm{mV}$ error on voltage (see below).

The usual Nernst equation describes the near-equilibrium behavior of
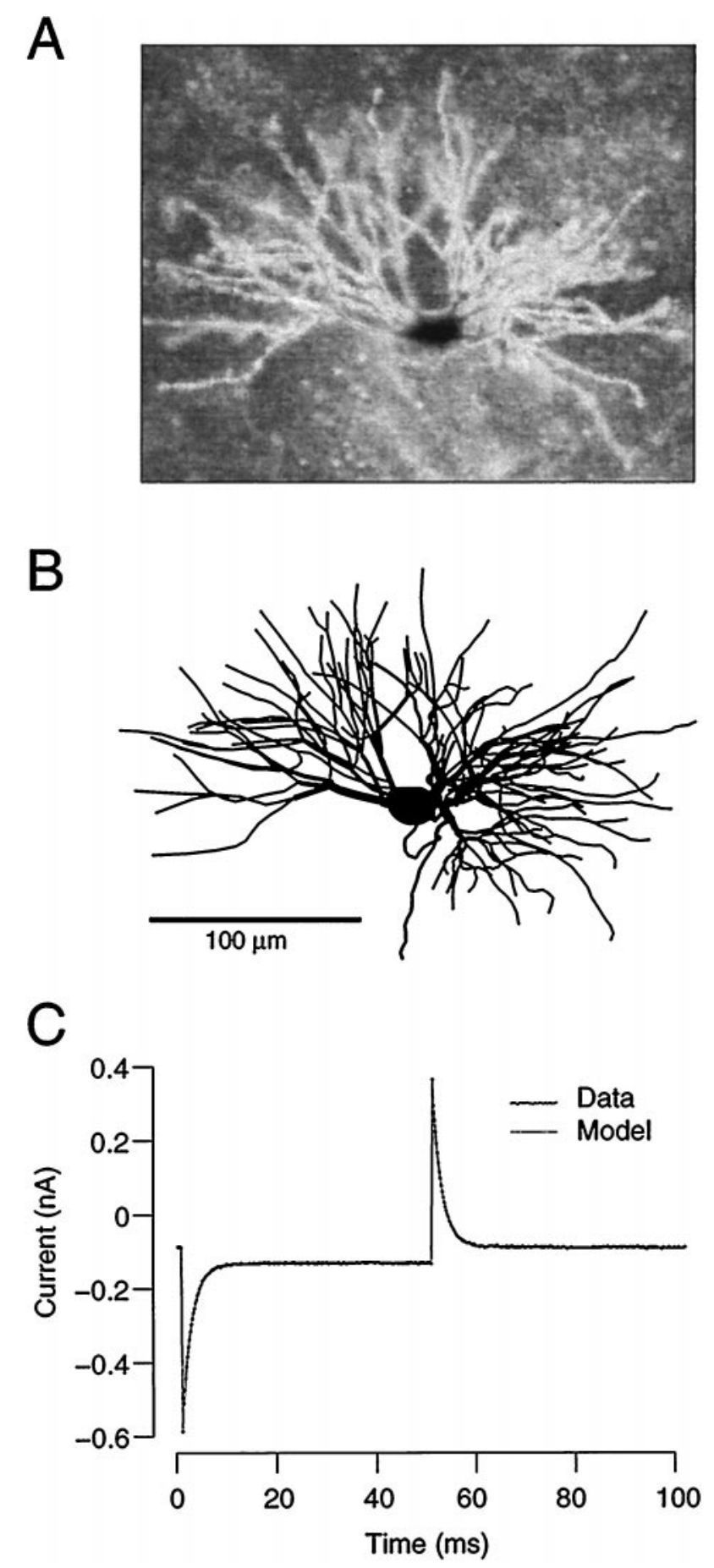

Figure 1. Recording, staining, reconstruction, and simulation based on of the same cellular geometry. $A$, Thalamic relay cell from rat ventrobasal nucleus, intracellularly recorded in slices (Huguenard and Prince, 1992). $B$, Three-dimensional reconstruction of the same cell. The complete dendritic arbor (of which only part appears in $A$ ) was reconstructed from thin serial sections. $C$, Computational model of the same cell. The simulation (continuous line) is compared with passive responses obtained while recording that cell (noisy trace). The adjustment of the model to the experimental response by a simplex fitting procedure provides estimates of passive parameters (see Results).

ion channels in which the current is described by Ohm's law. Because of the nonlinear and far-from-equilibrium behavior of calcium currents, a different formalism must be used (Hille, 1992), such as the constant-field equations: 


\section{Dissociated cells}

\section{A1}

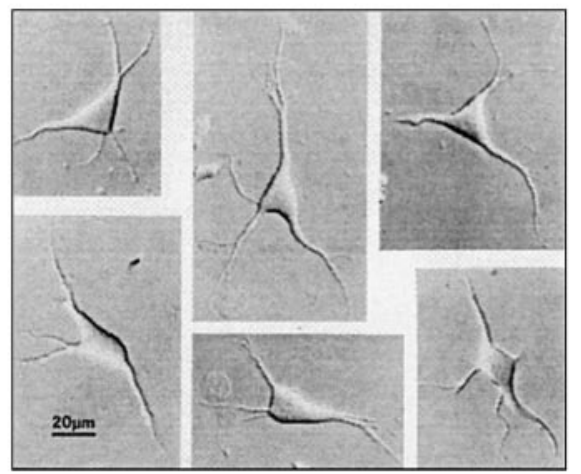

$\mathrm{A} 2$

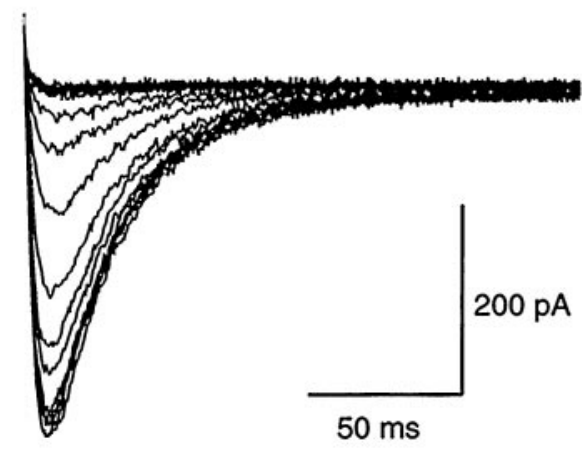

Model

\section{B1}

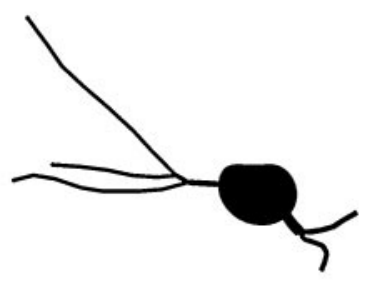

$\overline{20 \mu \mathrm{m}}$
B2

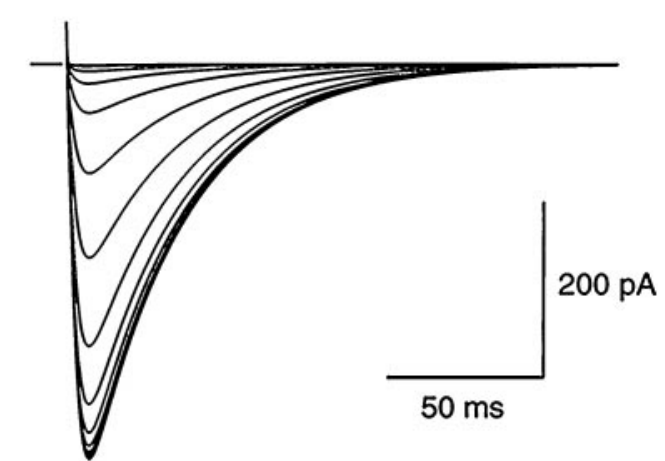

Figure 2. Low amplitudes of T-current in dissociated TC cells under voltage clamp. A1, Typical structure of dissociated TC cells, where most of the dendrites were removed by the dissociation procedure, leaving soma and proximal dendrites intact. $A 2$, Voltage-clamp recordings of the T-current in a dissociated TC cell. The voltage-clamp protocol consisted in conditioning the cell at various voltage levels (from -125 to $-60 \mathrm{mV}$ ) for 1 sec and then stepping the voltage to $-30 \mathrm{mV}$, revealing the transient activation of the current. The peak current was $\sim 400 \mathrm{pA}$ (different cell than that shown in $A 1$ ). $B 1$, Model of a dissociated TC cell, consisting of the soma with proximal bits of dendrites, adjusted from the input capacitance of the model. B2, Same voltage-clamp protocol as in $A 2$, simulated with the dissociated cell model. The model reproduces the peak amplitude of the T-current in dissociated cells with a moderate density of T-channels (permeability of $1.7 \times 10^{-5} \mathrm{~cm} / \mathrm{sec}$ ). This procedure provides an estimate of the perisomatic T-current density in TC cells. All experiments and simulations at $24^{\circ} \mathrm{C}$.

$$
\begin{aligned}
& I_{\mathrm{T}}=\bar{P}_{\mathrm{Ca}} m^{2} h G\left(V, \mathrm{Ca}_{\mathrm{o}}, \mathrm{Ca}_{\mathrm{i}}\right) \\
& \dot{m}=-\frac{1}{\tau_{\mathrm{m}}(V)}\left(m-m_{\infty}(V)\right) \\
& \dot{h}=-\frac{1}{\tau_{\mathrm{h}}(V)}\left(h-h_{\infty}(V)\right),
\end{aligned}
$$

where $\bar{P}_{\mathrm{Ca}}$ (in centimeters per second) is the maximum permeability of the membrane to $\mathrm{Ca}^{2+}$ ions, and $m$ and $h$ are, respectively, the activation and inactivation variables. $G\left(V, C a_{\mathrm{o}}, C a_{\mathrm{i}}\right)$ is a nonlinear function of voltage and ionic concentrations:

$$
G\left(V, \mathrm{Ca}_{\mathrm{o}}, \mathrm{Ca}_{\mathrm{i}}\right)=Z^{2} F^{2} V / R T \frac{\mathrm{Ca}_{\mathrm{i}}-\mathrm{Ca}_{\mathrm{o}} \exp (-Z F V / R T)}{1-\exp (-Z F V / R T)},
$$

where $Z=2$ is the valence of calcium ions, $F$ is the Faraday constant, $R$ is the gas constant, and $T$ is the temperature in Kelvins. $\mathrm{Ca}_{\mathrm{i}}$ and $\mathrm{Ca}_{\mathrm{o}}$ are the intracellular and extracellular $\mathrm{Ca}^{2+}$ molar concentrations, respectively.

The expressions for steady-state activation and inactivation functions were first obtained from voltage-clamp experiments on dissociated TC cells (Huguenard and Prince, 1992). The activation function was empirically corrected to account for the contamination of inactivation (Huguenard and McCormick, 1992). An overall hyperpolarizing shift of $2 \mathrm{mV}$ was applied to compensate for screening charge (voltage-clamp experiments on dissociated cells were done using $3 \mathrm{~mm}$ extracellular $\mathrm{Ca}^{2+}$, whereas physiological conditions are $1.5-2 \mathrm{mM}$ ). In addition, an overall depolarizing shift of $3 \mathrm{mV}$ was necessary to reproduce the current-clamp simulations of TC cells in the present paper. The optimal functions that accounted for both voltage-clamp and current-clamp data on TC cells were:

$$
\begin{aligned}
m_{\infty}(V) & =1 /(1+\exp [-(V+56) / 6.2]) \\
h_{\infty}(V) & =1 /(1+\exp [(V+80) / 4]) .
\end{aligned}
$$

The voltage-dependent time constant for activation was:

$$
\begin{aligned}
\tau_{\mathrm{m}}(V)=0.204+0.333 /(\exp [-(V+131) / 16.7] & \\
& +\exp [(V+15.8) / 18.2])
\end{aligned}
$$

and for inactivation:

$$
\tau_{\mathrm{h}}(V)=\begin{array}{ll}
0.333 \exp [(V+466) / 66.6] & \text { for } V<-81 \mathrm{mV} \\
9.32+0.333 \exp [-(V+21) / 10.5] & \text { for } V>-81 \mathrm{mV} .
\end{array}
$$

These functions correspond to an external $\mathrm{Ca}^{2+}$ concentration of $2 \mathrm{mM}$ and a temperature of $36^{\circ} \mathrm{C}$. All voltage-clamp simulations were done at $24^{\circ} \mathrm{C}$ assuming $Q_{10}$ values of 2.5 for both $m$ and $h$, whereas current-clamp behavior was simulated at $34^{\circ} \mathrm{C}$.

Calcium handling was modeled by a first-order system representing 
$\mathrm{Ca}^{2+}$ pumps and buffers, as described by McCormick and Huguenard (1992), with a time constant of decay of $\mathrm{Ca}^{2+}$ of $5 \mathrm{msec}$. At equilibrium, the free intracellular $\mathrm{Ca}^{2+}$ concentration was $240 \mathrm{nM}$, and the extracellular $\mathrm{Ca}^{2+}$ concentration was $2 \mathrm{~mm}$, corresponding to a reversal potential of approximately $+120 \mathrm{mV}$.

Simplified models. To generate simplified representations of TC cells, a method was used that consisted of collapsing the dendritic arbor into fewer compartments. We have used a reduction method based on the conservation of axial resistance (modified from Bush and Sejnowski, 1993).

The method consists of merging dendritic branches into equivalent cylinders, which preserve the axial resistance of the original branches. If the cross-sectional area of the equivalent cylinder equals the sum of each individual cross-sectional area, this is equivalent to summing parallel resistances, because $1 / r=\Sigma_{\mathrm{j}} 1 / R(j)$, where $R(j)$ are the axial resistances of the collapsed branches. The radius $(r)$ of the equivalent cylinder is then given by:

$$
r=\sqrt{\sum_{\mathrm{i}} r_{\mathrm{i}}^{2}},
$$

where $r_{\mathrm{i}}$ are the radii of the collapsed branches.

The length $(l)$ of the equivalent cylinder is taken as an average of the lengths of the collapsed branches $\left(l_{\mathrm{i}}\right)$, weighted by their respective diameters $\left(r_{\mathrm{i}}\right)$, such as:

$$
l=\frac{\sum_{\mathrm{i}} l_{\mathrm{i}} r_{\mathrm{i}}}{\sum_{\mathrm{i}} r_{\mathrm{i}}} .
$$

This modification of the Bush-Sejnowski algorithm was added to accommodate the merging of branches of very different length, which is often encountered while reducing dendritic morphologies, such that of the reconstructed TC cell studied here.

Because the total membrane area is not conserved in this method, the reduced model may not have a correct input resistance. This is compensated by introducing in each equivalent cylinder a dendritic correction factor $\left(C_{\mathrm{d}}\right)$, which rescales the values of conductances $\left(g_{\mathrm{i}}\right)$ and membrane capacitance $\left(C_{\mathrm{m}}\right)$ in the dendrites such that:

$$
g_{\mathrm{i}}^{\prime}=C_{\mathrm{d}} g_{\mathrm{i}}, \quad C_{\mathrm{m}}^{\prime}=C_{\mathrm{d}} C_{\mathrm{m}} .
$$

$C_{\mathrm{d}}$ is estimated such that the reduced model has the correct input resistance and time constant (Bush and Sejnowski, 1993).

The three compartments of the simplified model had the following lengths $(l)$ and diameters (diam): $l=38.4 \mu \mathrm{m}$, and diam $=26 \mu \mathrm{m}$ for the soma $\left(\right.$ area, $\left.2624 \mu \mathrm{m}^{2}\right) ; l=12.5 \mu \mathrm{m}$, and diam $=10.3 \mu \mathrm{m}$ for the proximal segment (area, $403 \mu \mathrm{m}^{2}$ ); and $l=84.7 \mu \mathrm{m}$, and diam $=8.5 \mu \mathrm{m}$ for the distal segment (area, $2261 \mu \mathrm{m}^{2}$ ). The total area was $5289 \mu \mathrm{m}^{2}$. The dendritic correction factor was $C_{\mathrm{d}}=8.02$, as calculated from the ratio of the total surface area of the dendritic segments to their equivalent cylinders. A more accurate estimation of $C_{\mathrm{d}}=7.95$ was obtained by fitting simulations to voltage-clamp recordings until the threecompartment model had input resistance and other passive properties matching the reconstructed cell perfectly (see Fig. 11A2).

The equations for the three-compartment model were:

$$
\begin{gathered}
C_{\mathrm{m}} \dot{V}_{\mathrm{S}}=-g_{\mathrm{L}}\left[V_{\mathrm{S}}-E_{\mathrm{L}}\right]-I_{\mathrm{T}}\left(V_{\mathrm{S}}\right)-g_{\mathrm{SM}}\left[V_{\mathrm{S}}-V_{\mathrm{M}}\right] / A_{1} \\
C_{\mathrm{d}} C_{\mathrm{m}} \dot{V}_{\mathrm{M}}=-C_{\mathrm{d}} g_{\mathrm{L}}\left[V_{\mathrm{M}}-E_{\mathrm{L}}\right]-C_{\mathrm{d}} I_{\mathrm{T}}\left(V_{\mathrm{M}}\right)-g_{\mathrm{SM}}\left[V_{\mathrm{M}}-V_{\mathrm{S}}\right] / A_{2}
\end{gathered}
$$

$$
-g_{\mathrm{MD}}\left[V_{\mathrm{M}}-V_{\mathrm{D}}\right] / A_{2}
$$

$C_{\mathrm{d}} C_{\mathrm{m}} \dot{V}_{\mathrm{D}}=-C_{\mathrm{d}} g_{\mathrm{L}}\left[V_{\mathrm{D}}-E_{\mathrm{L}}\right]-C_{\mathrm{d}} I_{\mathrm{T}}\left(V_{\mathrm{D}}\right)-g_{\mathrm{MD}}\left[V_{\mathrm{D}}-V_{\mathrm{M}}\right] / A_{3}$,

where $V_{\mathrm{S}}, V_{\mathrm{M}}$, and $V_{\mathrm{D}}$ are the voltage of somatic, middle, and distal compartments, respectively. $C_{\mathrm{m}}=0.878 \mu \mathrm{F} / \mathrm{cm}^{2}$ is the membrane capacitance; $g_{\mathrm{L}}=0.0379 \mathrm{mS} / \mathrm{cm}^{2}$ is the leak conductance; $E_{\mathrm{L}}=-69.85 \mathrm{mV}$ is the leak reversal potential; $I_{\mathrm{T}}$ is the T-current (according to Eq. 1); $g_{\mathrm{SM}}$ $=5.19 \mu \mathrm{S}$ and $g_{\mathrm{MD}}=0.70 \mu \mathrm{S}$ are the axial conductances (derived from axial resistivity and cross-sectional area of the compartments); $A_{1}-A_{3}$ are the areas of each compartment (see above); and $C_{\mathrm{d}}=7.95$ is the dendritic correction. These values correspond to the optimal set of passive parameters obtained by fitting the passive responses of the three-compartment model to experimental voltage-clamp responses (see Results).

A single-compartment model was also generated, and its membrane area was adjusted such that this model matches passive voltage-clamp recordings (see Fig. $11 \mathrm{~B} 2$ ). The optimal model had a length and diameter of $100 \mu \mathrm{m}$ and $76.6 \mu \mathrm{m}$, respectively.

We used only one anatomically reconstructed TC cell in this study, in addition to morphologically simplified models. The behavior of the detailed and simplified models was nearly identical (see Results), which suggests that the particular details of the morphology of the cell were unimportant in the context of the present study. The behavior reported in this paper was extremely robust to changes in the values of the parameters, as illustrated by the nearly identical behavior obtained in models with different cable geometries.

All simulations were done using NEURON (Hines and Carnevale, 1997) on Sparc-20 and Ultra-1 workstations (Sun Microsystems, Mountain View, CA).

\section{RESULTS}

We begin by showing how the thalamic relay cell model was successively constrained by the reconstructed dendritic morphology of a cell recorded experimentally, by voltage-clamp recordings to set its passive properties, by dissociated cell recordings to set its perisomatic T-current density, and by intact-cell recordings to set the T-current density in distal dendrites ("distal" will be used in this paper to refer to the dendritic region $>11 \mu \mathrm{m}$ from the soma). The properties of TC cells in voltage clamp and current clamp are then examined in terms of dendritic T-current. Finally, simplified models of the TC cell are generated and studied in the same context.

\section{Morphology and passive properties}

A TC cell from rat ventrobasal nucleus (shown in Fig. 1A) (also see Huguenard and Prince, 1992) was reconstructed using a three-dimensional tracing system. The reconstructed TC cell is shown in Fig. $1 B$ (see Materials and Methods for details concerning the tracing of the cell). There were 11 primary dendrites, having a total length of $7095 \mu \mathrm{m}$; the total membrane area of the cell was $23,980.5 \mu \mathrm{m}^{2}$, including $2625 \mu \mathrm{m}^{2}$ for the soma, which was $\sim 20-25 \mu \mathrm{m}$ in diameter (assuming that a $0.1 \mu \mathrm{m}$ error on diameters leads to approximately $\pm 9 \%$ error on the total membrane area). The dendritic arborizations tended to be organized in a bush-like structure, similar to previous morphological observations (Jones, 1985).

Voltage-clamp recordings of passive responses obtained in that cell are shown in Fig. $1 A$. These recordings were used to estimate the passive parameters by fitting the model to the data (Fig. 1C). Because model and data correspond to the exact same cellular geometry, this procedure leads to a unique set of passive parameters if they are uniform (Rall et al., 1992).

To perform passive fitting, leak currents were inserted in all compartments of the reconstructed cell model. The values of the passive parameters [leak conductance $\left(g_{\mathrm{L}}\right)$, leak reversal potential $\left(E_{\mathrm{L}}\right)$, axial resistivity $\left(R_{\mathrm{a}}\right)$, and specific membrane capacitance $\left(C_{\mathrm{m}}\right)$ ] and the electrode series resistance $\left(R_{\mathrm{s}}\right)$ were obtained by fitting the simulations to experimental data using a simplex algorithm (Press et al., 1986). At each iteration of the simplex algorithm, the model was run, and the root mean squared (rms) error between the experimental recording and the model was minimized. This procedure was repeated from different initial conditions to avoid unstable values of parameters. The values of passive parameters were considered uniform and were consistent with the values estimated from the recordings. Approxi- 
mately 50-300 iterations were required to converge to a minimum error.

The optimal set of values obtained was $C_{\mathrm{m}}=0.878 \mu \mathrm{F} / \mathrm{cm}^{2} ; R_{\mathrm{a}}$ $=173 \Omega \mathrm{cm} ; g_{\mathrm{L}}=0.0379 \mathrm{mS} / \mathrm{cm}^{2} ; E_{\mathrm{L}}=-69.85 \mathrm{mV}$; and $R_{\mathrm{s}}=8.1$ $\mathrm{M} \Omega$. This optimal set was obtained from different initial conditions with ranges of values tested of $0.2-2 \mu \mathrm{F} / \mathrm{cm}^{2}, 50-500 \Omega \mathrm{cm}$, $0.02-0.2 \mathrm{mS} / \mathrm{cm}^{2},-70$ to $-80 \mathrm{mV}$, and $1-40 \mathrm{M} \Omega$, respectively. The ranges of parameter values yielding similar fitting errors (within a $2 \mathrm{pA}$ maximal rms error) were $C_{\mathrm{m}}=0.856-0.899$ $\mu \mathrm{F} / \mathrm{cm}^{2} ; R_{\mathrm{a}}=147-200 \Omega \mathrm{cm} ; g_{\mathrm{L}}=0.0376-0.0383 \mathrm{mS} / \mathrm{cm}^{2} ; E_{\mathrm{L}}=$ $-69.72--69.97 \mathrm{mV}$; and $\mathrm{R}_{\mathrm{s}}=7.0-9.5 \mathrm{M} \Omega$. These ranges were obtained by varying each parameter individually around the optimal fit. A more detailed analysis, in which the search procedure was based on experimental precision or on experimental confidence intervals of electrophysiological and morphological measurements, yielded correspondingly larger acceptable ranges of values (Neubig and Destexhe, 1997) (M. Neubig and A. Destexhe, unpublished data).

Because the window current of $I_{\mathrm{T}}$ may affect the resting membrane potential of the cell, the same fitting was also performed in the presence of somatic-dendritic distribution of T-current. In this case, the values obtained were very close (within SE) to that of the passive fitting, except for the leak reversal potential that needed to be readjusted to compensate for the window current, leading to more negative values $\left(E_{\mathrm{L}}=-70.1\right.$ to $-73.4 \mathrm{mV}$ for dendritic T-current densities of $1.7 \times 10^{-5}$ to $12.5 \times 10^{-5}$ $\mathrm{cm} / \mathrm{sec}$; see below).

In these conditions, the electrotonic length of the longest dendrite was 0.34 space constants (as calculated using the optimal set of passive parameters shown above). The attenuation characteristics of the cell were estimated as follows. A current pulse of 10 msec and $0.1 \mathrm{nA}$ was injected in the middle of a representative terminal branch in the intact-cell model with passive currents. The attenuation was calculated by measuring the maximal voltage deflections evoked by this current injection, there and at the soma. The ratio obtained was $\sim 10$-fold $(0.098)$. The opposite protocol was also followed (current injected in soma while measuring in dendrites), and the ratio of voltage deflections was close to unity (0.91).

This TC cell is therefore relatively compact electrotonically, contrary to RE cells analyzed with similar methods (see Destexhe et al., 1996b) but similar to the conclusions of previous studies on TC cells (Bloomfield et al., 1987; Crunelli et al., 1987). Further comparison is difficult, however, because these studies were on a different animal, using different types of recording electrodes, different passive parameters, and a different method to estimate the electrotonic length.

\section{Density of T-current in soma and proximal dendrites}

Acutely dissociated neurons were used to characterize the T-current in TC cells (Huguenard and Prince, 1992). This preparation is very useful because the dissociation procedure removes most of the dendritic arbor, leaving the soma intact with proximal bits of dendrites (Fig. 2A1). This preparation therefore leads to very compact cells, in which voltage-clamp recordings can be made with minimal space clamp errors. The kinetics of the T-current used in the present paper (see Materials and Methods) were obtained from such recordings (see Huguenard and McCormick, 1992; Huguenard and Prince, 1992).

As illustrated in a previous model (Destexhe et al., 1996b), another advantage of the dissociated cell preparation is that it allows a direct estimate of the T-current density in the periso- matic region of the cell. This estimation was performed by matching a dissociated cell model to voltage-clamp recordings of the T-current in dissociated TC cells. The model used is shown in Figure $2 B 1$ and was obtained by adjusting the geometry of the model to the input capacitance measured in experimental recordings (see Materials and Methods).

Voltage-clamp recordings in dissociated TC cells show peak T-current amplitudes of $\sim 400$ pA (Fig. 2A2). Similar T-current peak amplitudes were obtained assuming a uniform density of T-current in the dissociated cell model $\left(1.7 \times 10^{-5} \mathrm{~cm} / \mathrm{sec}\right.$; Fig. 2B2). A range of T-current densities of $0.5-3.0 \times 10^{-5} \mathrm{~cm} / \mathrm{sec}$ reproduced the range of $\mathrm{T}$-current amplitudes measured in dissociated TC cells ( $350 \pm 27 \mathrm{pA} ; n=49$; from Coulter et al., 1989; and $280 \pm 23 \mathrm{pA} ; n=26$; from Huguenard and Prince, 1992).

\section{Increased density of T-current in more distal dendrites}

The presence of T-current was demonstrated in the dendrites of TC cells by optical imaging techniques (Munsch et al., 1997; Z hou et al., 1997). Given the fact that intact TC cells have a considerably more extended dendritic area than dissociated TC cells, this would predict a higher T-current amplitude in intact TC cells than shown in Figure $2 A 2$ for dissociated cells. This is indeed the case, as demonstrated by voltage-clamp recordings of intact TC cells (Fig. 3). The maximal T-current amplitude ranged from $\sim 2$ to 8.3 $\mathrm{nA}$ in different intact cells $(5.8 \pm 1.7 \mathrm{nA} ; n=7)$, which is on average $\sim 16-21$ times larger than in dissociated cells.

The model of the reconstructed TC cell was used to estimate the range of $\mathrm{T}$-current needed in dendrites to account for these data. As shown in Fig. 4, the density of T-current estimated from dissociated cells $\left(1.5-2.0 \times 10^{-5} \mathrm{~cm} / \mathrm{sec}\right)$ was insufficient to reproduce T-current amplitudes comparable to intact cells (Fig. $4 A$ ), even when the same density was extended to the entire dendritic tree (Fig. 4B). To obtain T-current peak amplitudes of $\sim 2 \mathrm{nA}$ and more, an increased density of T-current had to be assumed in distal dendrites (Fig. 4C,D). To reproduce peak amplitude in the range of $2-7 \mathrm{nA}$ of Figure 3 , the range of dendritic densities needed in the model were of $1.7-6.5 \times 10^{-5}$ $\mathrm{cm} / \mathrm{sec}$ for low series resistance $\left(R_{\mathrm{s}}=0.01 \mathrm{M} \Omega\right)$ and $2.5-50 \times$ $10^{-5} \mathrm{~cm} / \mathrm{sec}$ for high series resistances $\left(R_{\mathrm{s}}=12 \mathrm{M} \Omega\right)$, which is up to 29 times the density in the soma.

\section{Distal dendritic T-currents affect current-voltage relations}

A further indication for the presence of higher density of T-current in dendrites is obtained from the properties of the current-voltage $(I-V)$ relations. $I-V$ curves obtained from voltage-clamp recordings of TC cells show a marked difference between dissociated (Fig. $5 A$ ) and intact cells (Fig. $5 B$ ). Not only the maximum $\mathrm{T}$-current reaches much higher values, as shown in the previous section, but the shape of the $I-V$ curve is different; the peak occurs at approximately -40 to $-30 \mathrm{mV}$ in dissociated TC cells, whereas in intact cells, the $I-V$ curve was significantly shifted, peaking at -70 to $-60 \mathrm{mV}$.

In the dissociated cell model, simulated $I-V$ curves had a behavior consistent with experimental data (Fig. 5, compare $A, C)$. In intact cells, however, the behavior depended markedly on the density of the T-current. With higher T-current densities in distal dendrites, the $I-V$ curve was comparable to that recorded in intact cells during experiments (Fig. 5, compare $B, D$, circles). On the other hand, with uniform T-current densities, the $I-V$ curves were not consistent with experimental observations, neither for the peak amplitude, which was too low, nor for the position of the 


\section{Intact cells}

A

Figure 3. High amplitudes of T-current in intact TC cells under voltage clamp. Inactivation protocol in four TC cells $(A-D)$ recorded in thalamic slices of the ventrobasal nucleus. For each cell, the voltage-clamp protocol giving rise to the largest peak current is shown. The inactivation protocol consisted of conditioning the cell at various voltage levels (from -105 to $-40 \mathrm{mV}$ ) $(-55 \mathrm{mV}$ in $A,-65 \mathrm{mV}$ in $B,-60 \mathrm{mV}$ in $C,-45 \mathrm{mV}$ in $D$ ). For comparison, a similar protocol in a dissociated cell is shown in (P12); recording temperature was $24^{\circ} \mathrm{C}$ in all cases. for $1 \mathrm{sec}$ and then stepping the voltage to a fixed voltage value the bottom at the same calibration. All cells were the same age

\section{Dissociated cell}

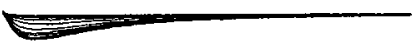

C

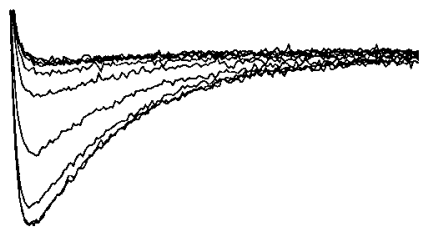

B

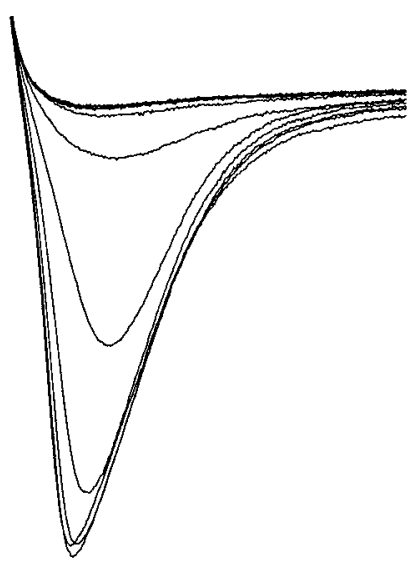

peak current, which was too depolarized (Fig. 5D, squares). By varying parameters (see below), we found that $I-V$ curve shift were consistent with those observed in experiments only when the density of T-current was significantly increased in distal dendrites. Voltage-clamp simulations using the intact-cell model further showed that the $I-V$ curve shift is attributable to poor voltage-clamp of the cell, which could be attributable to spaceclamp and/or series resistance artifacts. During a somatic voltage clamp, the dendritic T-channels are not easily controllable, as shown previously in simulated thalamic reticular cells (Destexhe et al., 1996b). The same phenomenon occurs for TC cells as shown in Fig. 6. From a holding potential of $-115 \mathrm{mV}$, stepping the voltage to a hyperpolarized value $(-65 \mathrm{mV})$, at which only few T-channels should open, activates $\sim 10 \%$ of the total T-current available for a uniform density of $1.7 \times 10^{-5} \mathrm{~cm} / \mathrm{sec}$ (Fig. 6A). On the other hand, with high distal dendritic densities of T-current, the same protocol led to activation of almost the totality of the available T-current (Fig. 6B). In this case, a lowthreshold spike was elicited in the dendrites and therefore the recorded current showed anomalously large currents at the soma. The inflection of the current trace in Figure $6 \mathrm{~B}$ is indeed indicative of poor voltage control (see Huguenard et al., 1988). Consequently, the peak of the $I-V$ curve will occur at more hyperpolarized values because of the poor control over dendritic T-channels.

The shift of $I-V$ curve caused by poor voltage control was further illustrated by showing the effect of various parameters
(Fig. 7). The $I-V$ curve shift was affected by the total amount of T-channels (Fig. 7A) and the series resistance of the voltageclamp electrode (Fig. 7B). The T-channel distribution also affected the $I-V$ curve shift both for distributions with same peak current (Fig. $7 C$ ) and for distributions where the total amount of T-channels was kept constant (Fig. 7D). These properties show that the $I-V$ curve shift is attributable to a poor control over some, possibly dendritic, portion of T-channels in the cell. This is in agreement with a previous modeling study, which also concluded that imperfect space clamp results in alterations of $I-V$ curves (Müller and Lux, 1993).

\section{A test for the quality of voltage control over the dendrites}

The poor voltage clamp evidenced above should be detectable by appropriate experiments. Tail currents can be used to assess the quality of voltage control (Huguenard, 1998). This protocol is illustrated in Fig. 8. In the dissociated cell model (Fig. 8A), the amplitude of the tail currents follows closely the time course of activation and inactivation of the current, as expected from an experiment with good clamp (Huguenard, 1998). On the other hand, the same protocol applied to the intact-cell model produced significant deviations of tail current amplitudes (Fig. 8B). Such deviations occurred despite the fact that the model of Figure $8 B$ had moderate density of dendritic T-current. The mismatch between tail currents and T-current activation was paralleled with poor clamp in this model. Because tail currents can be easily 


\section{Intact cell model}

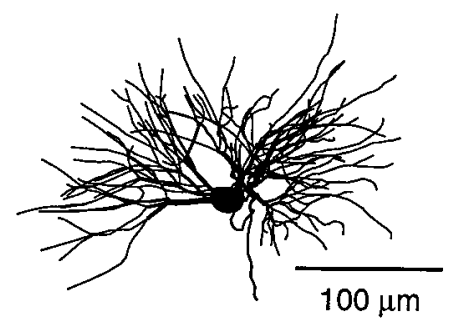

A

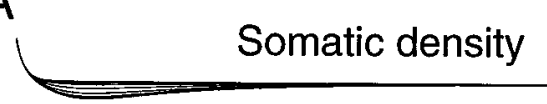

B

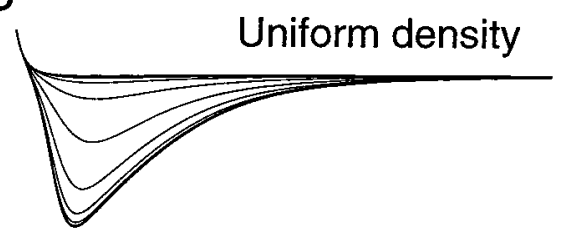

C

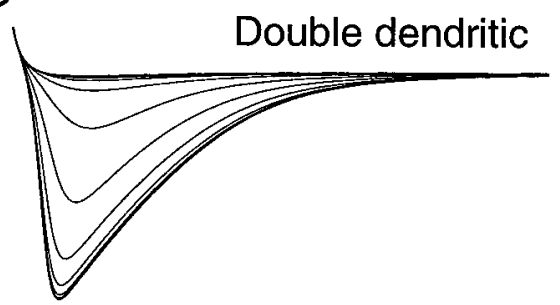

D

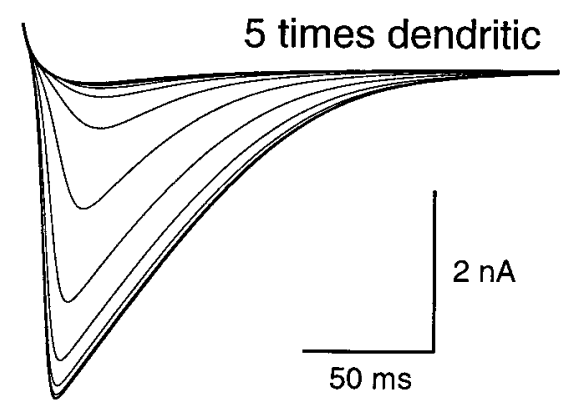

Figure 4. High densities of dendritic T-current are needed to match the $\mathrm{T}$-current amplitude recorded in intact TC cells. The model shows the same inactivation protocol using different distributions of T-current. In all cases, the perisomatic $I_{\mathrm{T}}$ density was compatible with recordings in dissociated cells (permeability of $1.7 \times 10^{-5} \mathrm{~cm} / \mathrm{sec}$ in soma and proximal dendrites), whereas the density of $I_{\mathrm{T}}$ in distal dendrites was varied. $A$, No dendritic T-current. $I_{\mathrm{T}}$ was limited to the perisomatic region. $B$, Uniform T-current. $I_{\mathrm{T}}$ had the same density throughout the neuron. $C$, Twice dendritic. $I_{\mathrm{T}}$ density was twice in distal dendrites compared with the perisomatic density. $D$, Five times dendritic. Distal dendrites had five times as much T-current density as in the perisomatic region. The latter produced peak $I_{\mathrm{T}}$ amplitudes comparable to the average value of intact TC cells recorded in slices (Fig. 3). All simulations at $24^{\circ} \mathrm{C}$.

measured experimentally, this figure therefore provides an important experimentally verifiable prediction to test that poor voltage clamp is responsible for significant alterations of T-current $I-V$ curves in intact TC cells.
Simulations therefore suggest that the voltage-clamp recordings of dissociated TC cells were always in conditions of good space clamp, as indicated by the well clamped voltage in soma and proximal dendrites (data not shown). On the other hand, simulations of intact TC cells clearly indicate poor control (see voltage traces in Fig. 6B), in agreement with the tail current test shown in Figure 8.

\section{Burst generation in TC cells with dendritic T-current}

A further argument in favor of dendritic T-current was given by current-clamp simulations. Current-clamp recordings were obtained in the cell shown in Figure $1 A$ and consisted of injecting depolarizing pulses from rest $(-73$ to $-74 \mathrm{mV})$. Current pulses of 50 and $75 \mathrm{pA}$ amplitude gave rise to low-threshold spikes (LTS) with one and two action potentials, respectively (Fig. 9A). In the model, assuming a uniform density of T-current based on voltageclamp recordings in dissociated TC cells, the same current-clamp protocol could not give rise to LTS (Fig. 9B), despite a large range of parameters explored, such as the resting level of the cell and the kinetics of $I_{\mathrm{T}}$.

With high densities of T-current in distal dendrites, LTS generation similar to the intact cell could be produced (Fig. 9C). One- and two-spike bursts were generated by 50 and $75 \mathrm{pA}$ current injection, respectively, whereas the one-spike burst had a longer latency (although not as long as in experiments). The latency could be increased by using more negative resting membrane potential (data not shown), but in this case the resting values were not in agreement with the data. The correct latency of the first burst may therefore depend on the presence of other currents not included here, such as $I_{\mathrm{h}}$, which is active at rest and therefore likely to affect the resting level of the cell (Pape, 1996).

Taking the number of spikes as the reference behavior, only a narrow range of $\mathrm{T}$-current densities gave rise to burst responses with one and two spikes as in Figure $9 A$. Too low densities did not produce LTS, as in the case of uniform T-current (Fig. 9B), whereas too high densities gave rise to a correct burst for $50 \mathrm{pA}$ current injection but generated an exceedingly powerful burst at $75 \mathrm{pA}$ (data not shown). Therefore, having access to the currentclamp recordings of the reconstructed TC cell constitutes a very strong constraint for the total amount of T-current in the cell. Correct burst behavior could be obtained using uniform high densities of T-current $\left(\sim 7 \times 10^{-5} \mathrm{~cm} / \mathrm{sec}\right)$, but that model was inconsistent with dissociated cells. Assuming that the perisomatic density of T-current was identical to that estimated from dissociated cells $\left(1.7 \times 10^{-5} \mathrm{~cm} / \mathrm{sec}\right)$, a relatively narrow range of T-current density in distal dendrites gave rise to burst generation consistent with experimental data. This type of T-channel distribution was in agreement with all voltage-clamp and currentclamp data.

Assuming a $\pm 3 \mathrm{mV}$ error on all voltages (the voltage of the experimental data of Fig. $9 A$ as well as the voltage of the kinetics of $I_{\mathrm{T}}$ ) gave a possible range of dendritic densities of T-current between $7.6 \times 10^{-5}$ and $12.5 \times 10^{-5} \mathrm{~cm} / \mathrm{sec}$, which is $\sim 4.5-7.6$ times the density of the soma.

To compare the above dendritic T-current permeabilities with published values, they were converted into conductances by simulating the calcium current using the Nernst relation (Hille, 1992). The range of dendritic T-current conductance obtained was $\sim 0.8-1.4 \mathrm{mS} / \mathrm{cm}^{2}\left(8-14 \mathrm{pS} / \mu \mathrm{m}^{2}\right)$. This estimated conductance range is slightly larger but close to the average T-current densities of $7-10 \mathrm{pS} / \mu \mathrm{m}^{2}$ measured in the dendrites of hippocampal pyramidal cells (Magee and Johnston, 1995). 
A

Figure 5. Current-voltage relationship in TC cells under voltage clamp. The graphs show the peak amplitude of T-current obtained during activation protocols under voltage clamp; each protocol consisted of conditioning the cell at $-105 \mathrm{mV}$ for $1 \mathrm{sec}$ and stepping to various voltage values (shown in abscissa). $A, I-V$ relation for the T-current in a dissociated TC cell. The peak current was of $\sim 0.4 \mathrm{nA}$ and occurred at $-40 \mathrm{mV}$. $B, I-V$ curve in an intact TC cell (same cell as in Fig. $3 C$ ). The peak T-current was here of $\sim 2.5 \mathrm{nA}$ and occurred at -60 $\mathrm{mV}$. The steep decline of the $I-V$ curve above $-60 \mathrm{mV}$ is probably attributable to incomplete block of outward currents by cesium. $C$, Dissociated cell model. A similar $I-V$ curve as in $A$ could be reproduced with moderate T-current density (permeability of $1.7 \times 10^{-5} \mathrm{~cm} / \mathrm{sec}$ ). $D$, Intact-cell model. In this case, the $I-V$ curve of the intact cell shown in $B$ could be reproduced using a larger T-current density in distal dendrites $\left(2.5 \times 10^{-5}\right.$ $\mathrm{cm} / \mathrm{sec})$ compared with the perisomatic region $(1.7 \times$ $10^{-5} \mathrm{~cm} / \mathrm{sec}$ ) and a series resistance of $R_{\mathrm{s}}=12 \mathrm{M} \Omega$ (circles). This $I-V$ curve is compared with the same simulation with uniform T-current density of $1.7 \times$ $10^{-5} \mathrm{~cm} / \mathrm{sec}$ (squares). All activation protocols consisted of conditioning the cell at $-115 \mathrm{mV}$ for $1 \mathrm{sec}$ and then stepping the voltage to the values indicated. The peak currents shown are leak-subtracted. All experiments and simulations at $24^{\circ} \mathrm{C}$.

C
Figure 6. Poor clamp together with distal dendritic T-currents alters current-voltage relations. Voltageclamp simulation of the intact TC cell model consisting of conditioning the cell at $-115 \mathrm{mV}$ for $1 \mathrm{sec}$ and stepping the voltage to $-65 \mathrm{mV}$. The voltage is shown in soma and distal dendrite, as well as the current. The maximal current that could be evoked (peak of the $I-V$ curve) is shown by dotted lines for comparison. $A$, uniform T-channel density of $1.7 \times 10^{-5} \mathrm{~cm} / \mathrm{sec}$ shows little current activation at $-65 \mathrm{mV}(0.187 \mathrm{nA})$, representing $\sim 10 \%$ of the total T-current. $B$, same simulation with high densities of T-current in dendrites $\left(1.7 \times 10^{-5} \mathrm{~cm} / \mathrm{sec}\right.$ perisomatic and $8 \times 10^{-5} \mathrm{~cm} / \mathrm{sec}$ in distal dendrites). In this case, large uncontrolled voltage transients occurred in both soma and dendrites, leading to a large peak current $(4.09 \mathrm{nA})$, representing $98 \%$ of the total available T-current. Series resistance was $12 \mathrm{M} \Omega$, and temperature was $24^{\circ} \mathrm{C}$ in both cases.
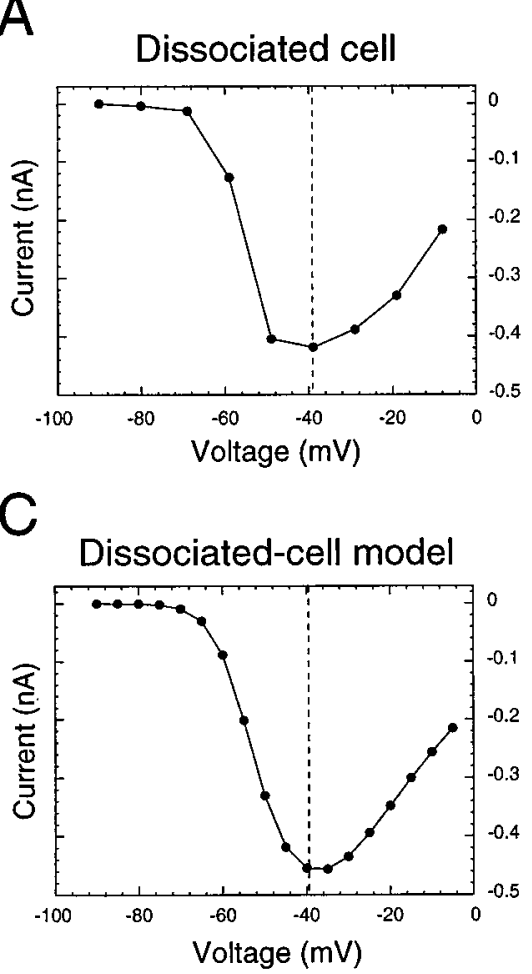

\section{A Uniform T-channel density}

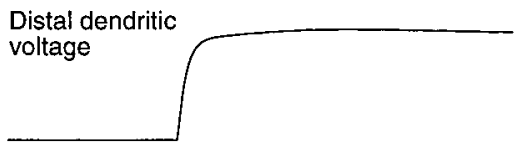

B

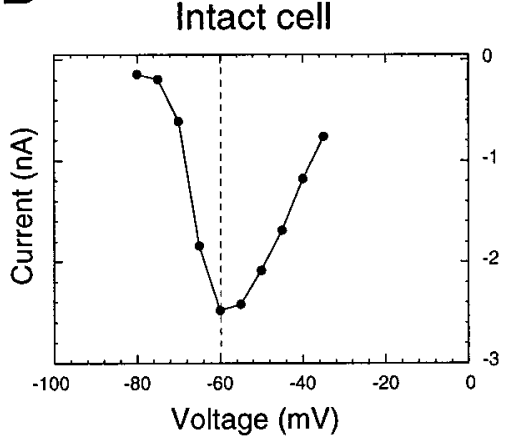

D

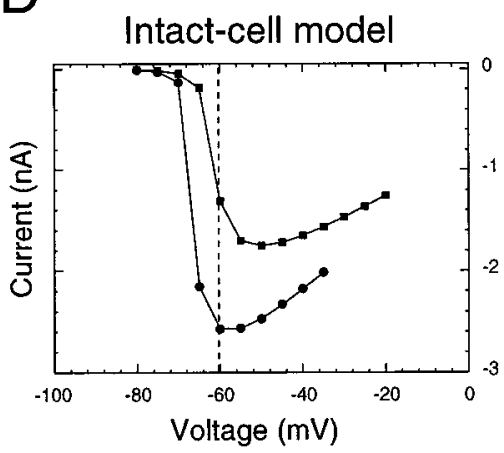

B

Distal dendritic T-channels
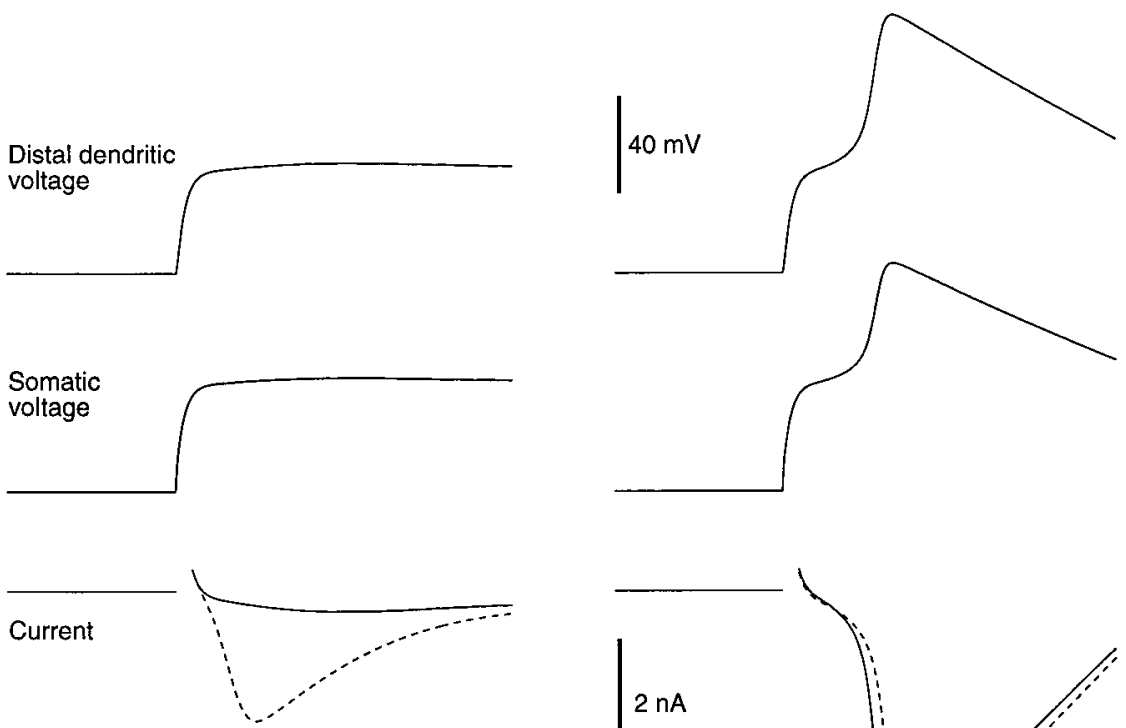

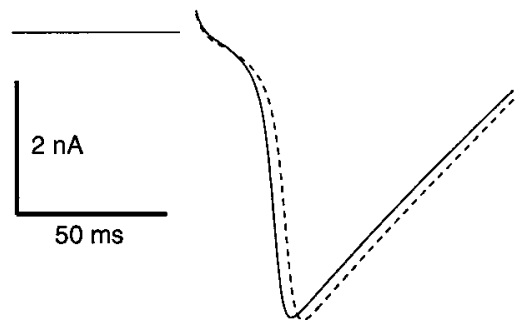

\section{T-channels can be controlled more efficiently if they are dendritic}

An important question is how does dendritic current location shape the burst of TC cells. To answer this question, the reconstructed TC cell was simulated using two different distributions of T-current with same total number of T-channels (Fig. 10, Somatic $\&$ dendritic, Somatic only). For increasing intensities of injected current, the cell successively generates passive responses, subthreshold LTS, and full-blown bursts with sodium spikes (Fig. $10 A$ ). The generation of these LTS responses shows differences between somatic and somatodendritic distributions of T-current, with LTS evokable by smaller current injections for somatic-only distributions (Fig. 10B). This property was already apparent from $I-V$ curves, in which somatically localized T-channels led to 
A

Figure 7. Poor clamp and dendritic T-current can explain the shift in the current-voltage curves in intact and dissociated TC cells. $A$, Effect of the total amount of T-channels. At $100 \%$, the perisomatic and dendritic T-current densities were of $1.7 \times 10^{-5}$ and $8 \times 10^{-5}$ $\mathrm{cm} / \mathrm{sec}$, respectively. The total density of T-current was uniformly decreased by a factor of $2(50 \%)$ and $4(25 \%)$. $B$, Effect of the series resistance. Same simulation as $100 \%$ in $A$, using three different values of the series resistance. $C$. Effect of the distribution of T-channels. Two different T-channel distributions were adjusted such as to get similar peak currents at the soma $\left(R_{\mathrm{s}}=5\right.$ $\mathrm{M} \Omega$ ). Somatic \& dendritic, $1.7 \times 10^{-5} \mathrm{~cm} / \mathrm{sec}$ perisomatic and $8 \times 10^{-5} \mathrm{~cm} / \mathrm{sec}$ in dendrites at $11 \mu \mathrm{m}$ and more from the soma ( $\sim 82 \%$ of membrane area). Somatic only, $42.7 \times 10^{-5} \mathrm{~cm} / \mathrm{sec}$ in soma and no T-current in dendrites. $D$, Same graph, but in this case the Somatic only density $\left(53.3 \times 10^{-5} \mathrm{~cm} / \mathrm{sec}\right)$ was adjusted such that the total number of T-channels was the same as for Somatic \& dendritic. All simulations at $24^{\circ} \mathrm{C}$.

\section{Total T-channels}

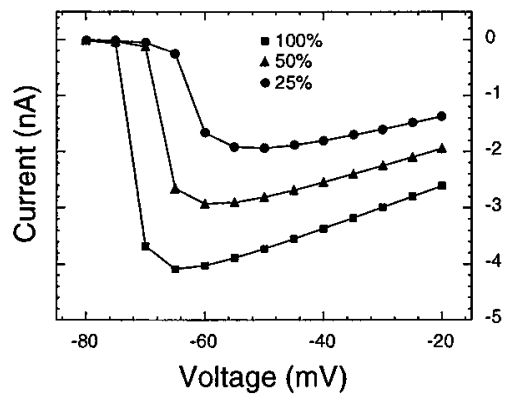

C

T-channel distribution

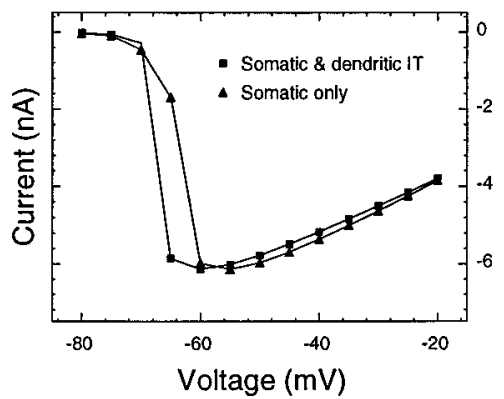

B

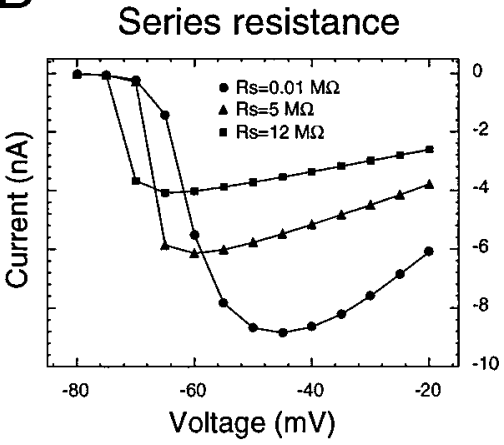

D

T-channel distribution

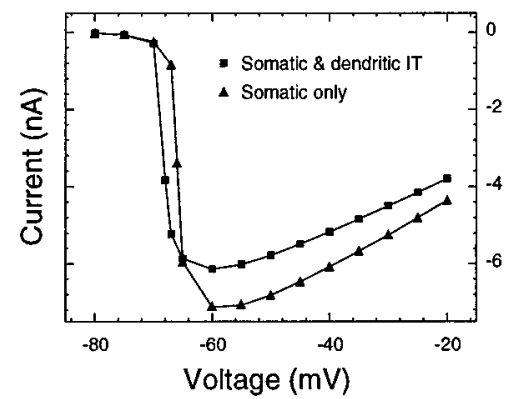

Figure 8. Tail currents are indicative of the quality of voltage control over the dendrites. Left panels, Tail currents. The cell was conditioned at $-115 \mathrm{mV}$ for $1 \mathrm{sec}$, and then the voltage was stepped to $-30 \mathrm{mV}$, leading to transient activation of the T-current. Tail currents are obtained when the voltage is stepped back to $-115 \mathrm{mV}$ at different instants during this activation. Right panels, Comparison of the time course of the T-current (continuous line) with the peak tail current amplitudes (squares), scaled to each other. A perfect match of these two currents is indicative of perfect clamp in the cell (Huguenard, 1998). A, Dissociated cell model. The tail currents match closely the activation of the T-current. $B$, Intact-cell model. In this case, the mismatch between tail currents and T-current activation was paralleled with poor clamp (T-current densities were $1.7 \times 10^{-5} \mathrm{~cm} /$ sec perisomatic and $2.5 \times 10^{-5} \mathrm{~cm} / \mathrm{sec}$ in distal dendrites). All currents were subtracted from leak and capacitive components $\left(24^{\circ} \mathrm{C}\right)$.

\section{A}

\section{Dissociated-cell model}
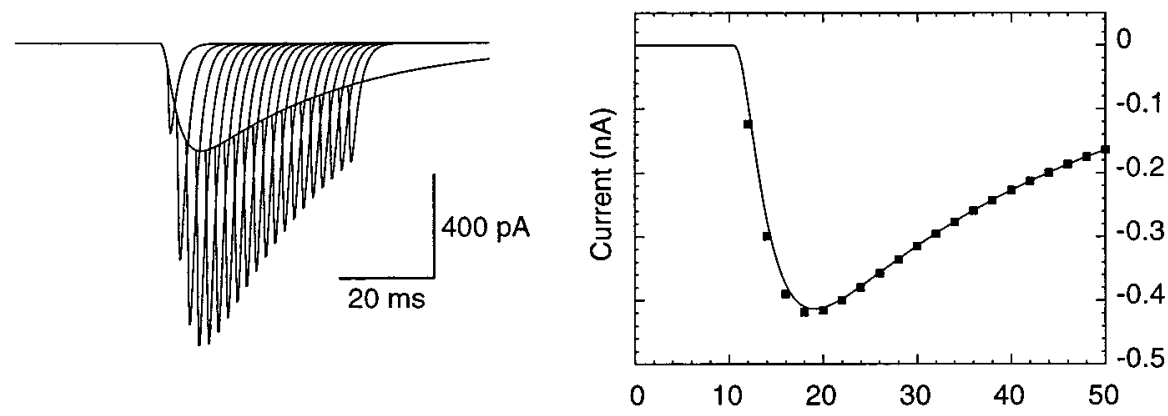

B
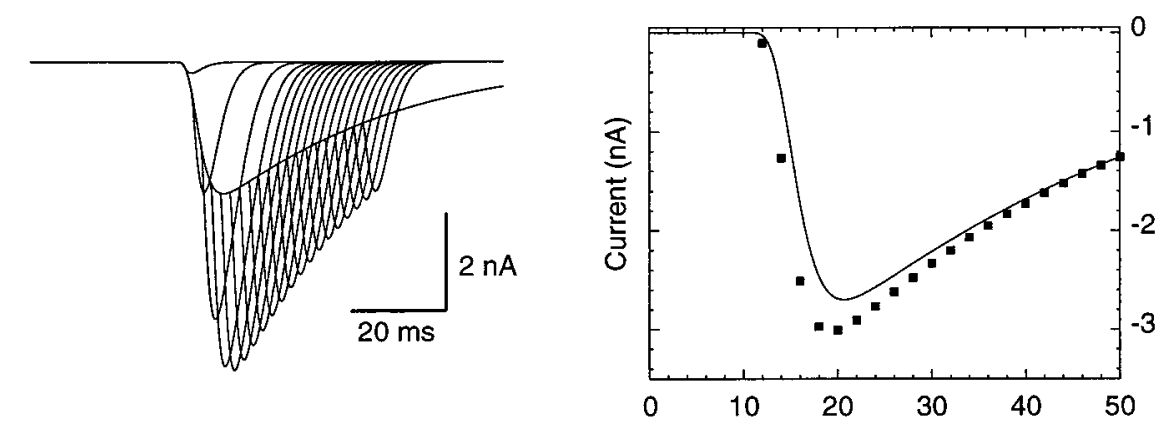

higher peak T-current amplitudes compared with T-channels distributed in dendrites (Fig. 7D, triangles). Therefore, localizing T-channels in the dendrites decreases the excitability of the cell with respect to LTS generation.

An equally important question is how these properties can be modulated by other currents in the dendrites. In particular, the dendrites of TC cells are densely covered by synaptic terminals from various excitatory and inhibitory neurons. Under conditions of tonic activity that characterizes active states (Steriade et al., 1990), TC cells are therefore bombarded by mixed excitatory and inhibitory inputs, which should lead to significant dendritic shunt. The effect of dendritic shunt conductances on burst generation is 


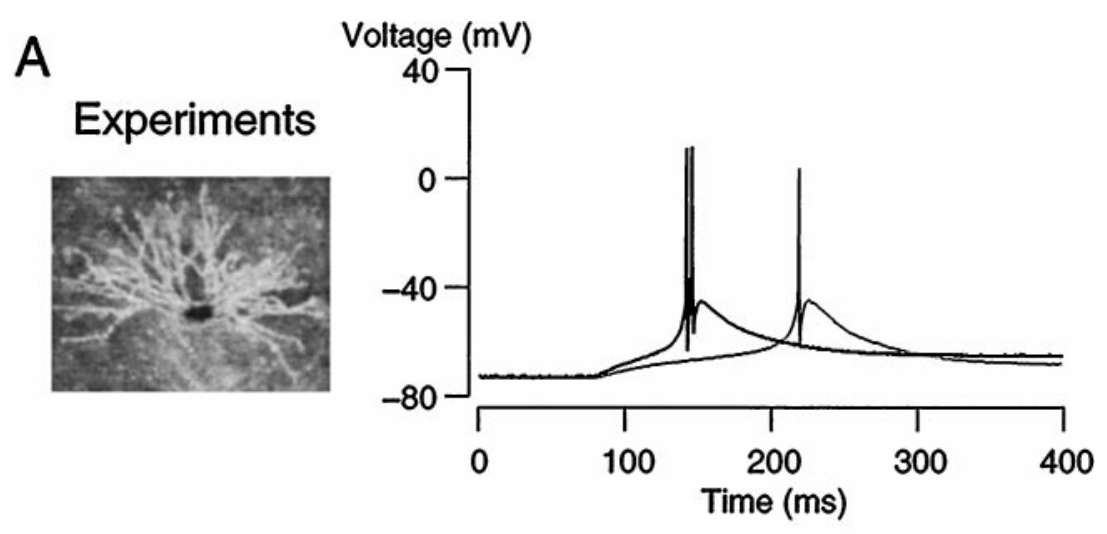

B

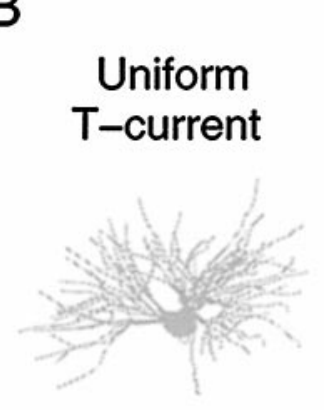

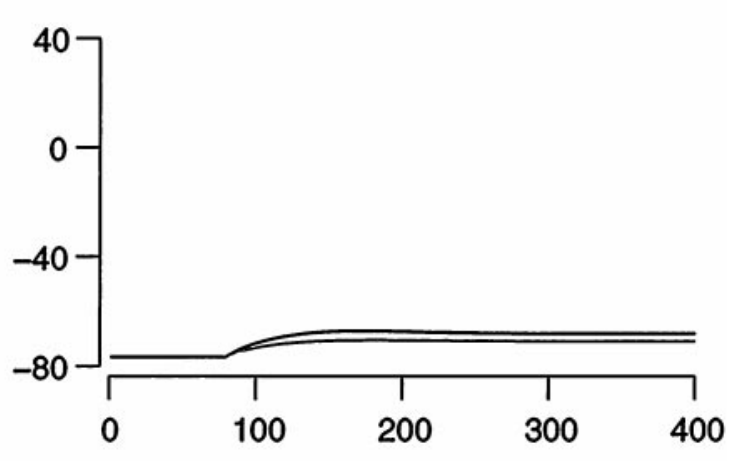

\section{C}

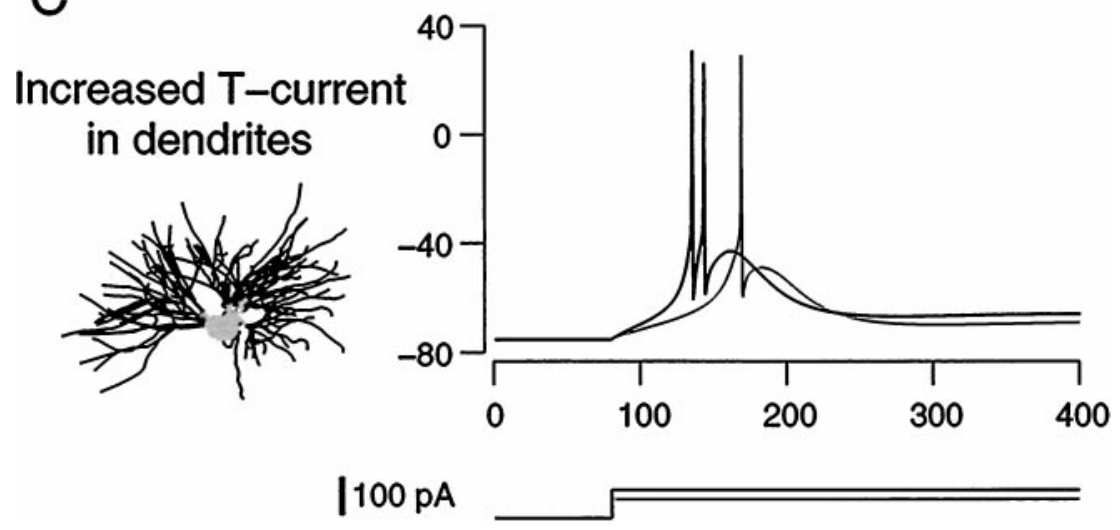

Figure 9. Correct low-threshold spike generation in intact TC cells requires high densities of dendritic T-current. Current-clamp recordings of LTS in the recorded intact TC cell are compared with simulations based on the same cellular geometry. $A$, Experimental recordings of LTS in the intact TC cell at rest using two different amplitudes of injected depolarizing current: 50 $\mathrm{pA}$ (thin trace) and $75 \mathrm{pA}$ (thick trace). B, Simulations of the same current injection did not generate LTS using a uniform density of T-current based on dissociated cells $\left(1.7 \times 10^{-5} \mathrm{~cm} / \mathrm{sec}\right) . C$, Successful LTS generation with increased density of T-current in distal dendrites. In $B$ and $C$, the gray levels indicate the density of T-current in different regions of the cell: $1.7 \times 10^{-5} \mathrm{~cm} / \mathrm{sec}$ (light gray) and $8.5 \times 10^{-5} \mathrm{~cm} / \mathrm{sec}$ (black). All experiments and simulations at $34^{\circ} \mathrm{C}$. depicted in Figure $10 C$. In this case, the differences between somatic only and somatic and dendritic T-channel localization are remarkably enhanced (Fig. 10C). In addition, the LTS response was less steep, leading to more "graded" bursting behavior in the presence of shunt conductances. More importantly, dendritic shunt shifted the LTS response curve more efficiently for dendritic T-channels (Fig. 10, compare Somatic \& dendritic curves in $B, C$ ) than for somatic T-current (Fig. 10, compare Somatic only curves). These simulations therefore show that the same amount of T-channels can be controlled differently if they are exclusively somatic or distributed throughout the dendrites. Possible functional consequences of this property in the behavior of TC cells in vivo will be considered in Discussion.

\section{Simplified models of TC cells}

To provide a simplified representation of somatodendritic interactions during low-threshold spike generation in TC cells, we have designed a simplified model by collapsing the dendritic structure into a few compartments based on the conservation of axial resistance, a theme previously proposed by Bush and Sejnowski (1993). A modified version of this method was used here (see Materials and Methods). The reduction was based on a partition of the cell into three regions, as considered previously: (1) the soma, (2) proximal dendrites (corresponding to those of dissociated cells), and (3) the remaining (distal) dendrites. Based on this partition, the collapse algorithm was applied to generate a reduced model with three compartments, each corresponding to the aforementioned regions. The model obtained is shown in Figure $11 A 1$.

The next step was to obtain passive properties consistent with experimental data. The simplified model was endowed with the same passive parameters as the detailed model, and a dendritic correction factor $\left(C_{\mathrm{d}}\right)$ was applied to the dendrites to compensate for their reduced membrane area (see Materials and Methods). The value of dendritic correction was adjusted by fitting the passive responses of the model to that obtained during voltageclamp recordings (Fig. 11 $A 2$ ). With $C_{\mathrm{d}}=7.95$ (range, 7.92-7.97) 


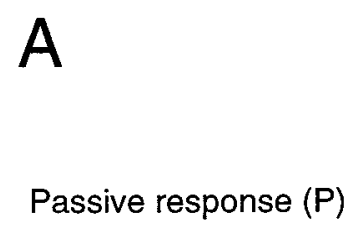

Subthreshold response (S)

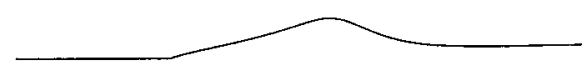

Burst response (B)

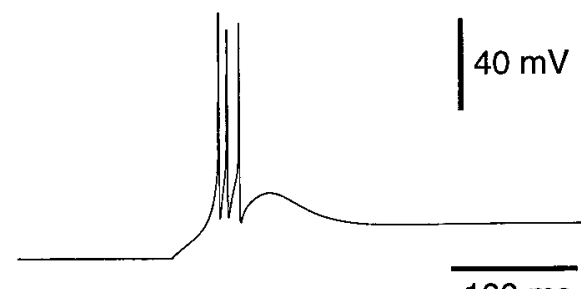

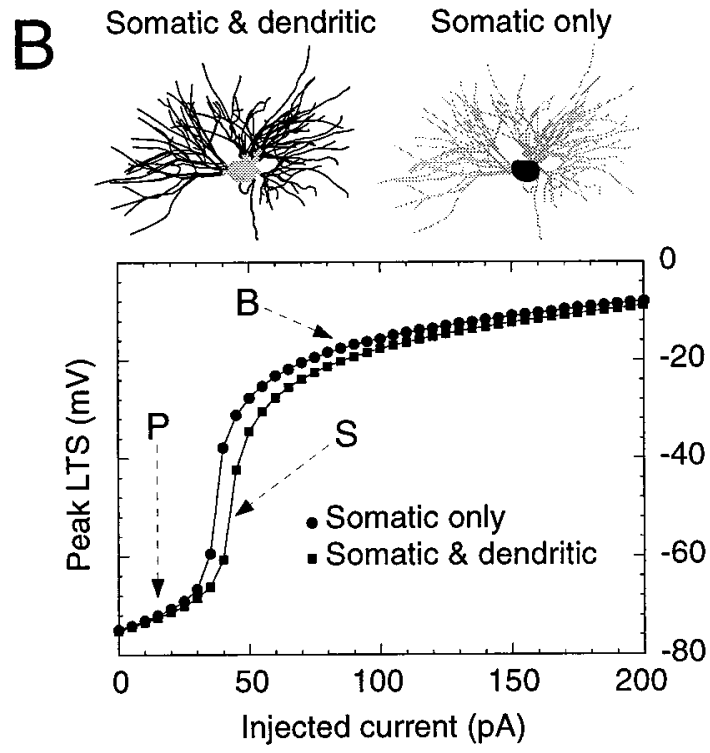

C

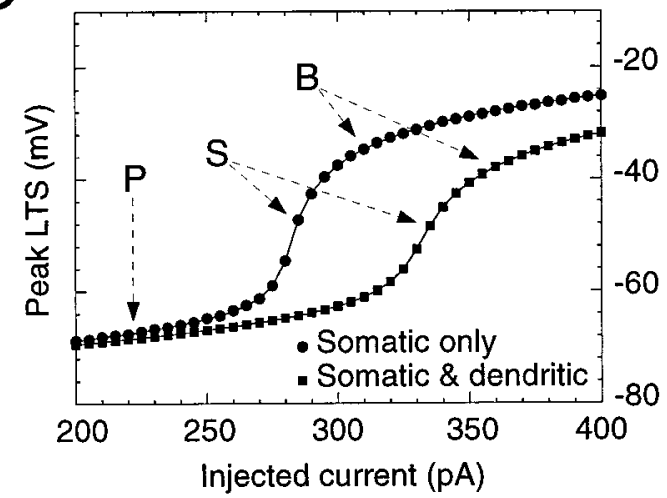

Figure 10. Consequence of dendritic T-current in shaping the burst response of thalamic relay cells. $A$, Three representative types of response to depolarizing current injection from rest: passive $(P)$, subthreshold $(S)$, and burst $(B)$ responses. $B$, LTS peak amplitude represented as a function of the amplitude of injected current in the soma. For this simulation, fast $\mathrm{Na}^{+}$and $\mathrm{K}^{+}$currents underlying action potentials were not included, and the reconstructed TC cell had two different somatodendritic distributions of T-current: Somatic \& dendritic $\left(1.7 \times 10^{-5} \mathrm{~cm} / \mathrm{sec}\right.$ perisomatic and $8.5 \times 10^{-5}$ $\mathrm{cm} / \mathrm{sec}$ dendritic) and Soma only (density of $56.53 \times 10^{-5} \mathrm{~cm} / \mathrm{sec}$ in soma with none in dendrites; adjusted such that the total number of T-channels was the same as for Somatic \& Dendritic). The fact that these two curves do not overlap shows the effect of channel segregation on burst generation in normal conditions. $C$, LTS peak amplitudes in the presence of dendritic shunt conductances. With a dendritic shunt conductance of $g_{\mathrm{L}}=0.15 \mathrm{mS} / \mathrm{cm}^{2}$, the burst response becomes significantly different whether the T-current is located in the dendrites or exclusively in the soma.

the model fitted the data remarkably well (Fig. 11A2). This value is close to the reduction ratio of dendritic membrane, which was 8.02 for this model.

When T-channels were inserted using somatic and dendritic densities as described in previous sections, the simplified model generated voltage-clamp behavior very close to the detailed model, with very similar peak amplitudes (Fig. 11A3, compare triangles, squares). With a slightly increased density of T-current in dendrites, the simplified model could match closely the complete $I-V$ curve of the detailed model (Fig. 11A3, compare circles, squares).

Using these T-current densities, the behavior was examined in current clamp. First, the somatodendritic density that matched closely the $I-V$ curve generated low-threshold responses very similar to the data and the detailed model (compare Figs. 11 $A 4$, 9). Second, like the detailed model, the genesis of correct lowthreshold bursts required increased densities of dendritic currents in the simplified model (Fig. 12A). This latter point suggests that high densities of dendritic calcium currents are needed to be consistent with all data, and that this conclusion is independent of the particular morphological details of the model.

The effects of the electrical separation of currents in the cell were tested with the three-compartment model (Fig. 12B). As in the detailed model, localizing T-channels in the dendrites diminished the excitability of the cell for LTS generation. These differences are markedly enhanced in the presence of dendritic shunt conductances (Fig. 12C), similar to the detailed model (compare with Fig. 10B,C). This demonstrates that these types of somatodendritic interactions do not need the precise dendritic morphology to be simulated, but they critically need an increased density of T-current in dendrites.

Finally, a single-compartment model of the TC cell was generated for comparison. A first possibility was to remove the dendrites from the detailed model, but in this case, the isolated soma did not generate bursts of action potentials and had an incorrect input resistance. A second possibility was to increase the membrane area until the model matched the input resistance of the intact cell. In this case, with passive properties identical to the 
3-compartment

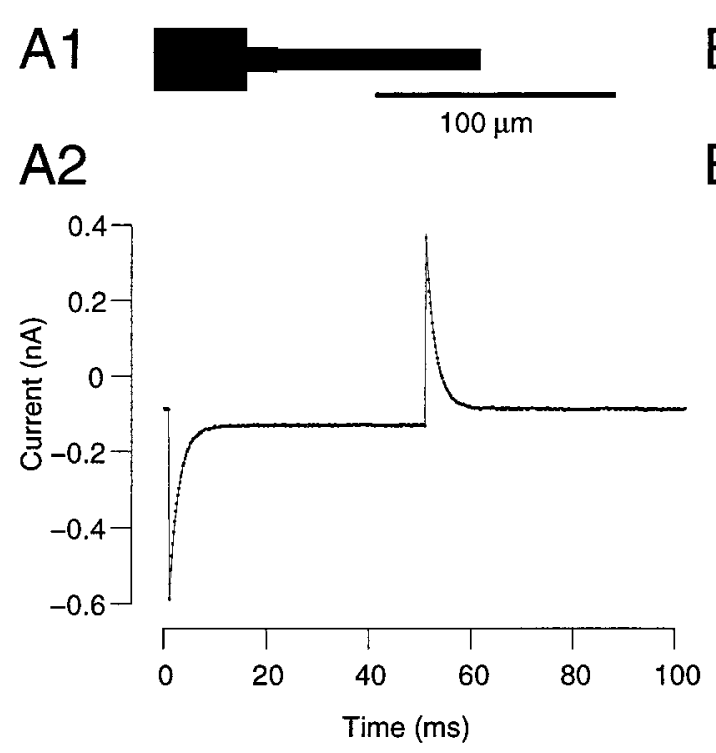

\section{1-compartment}

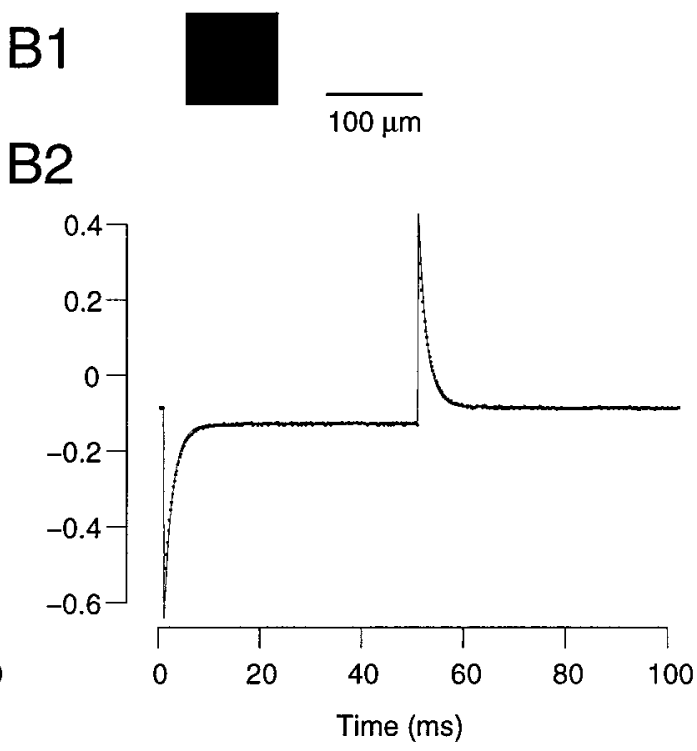

B3

A3
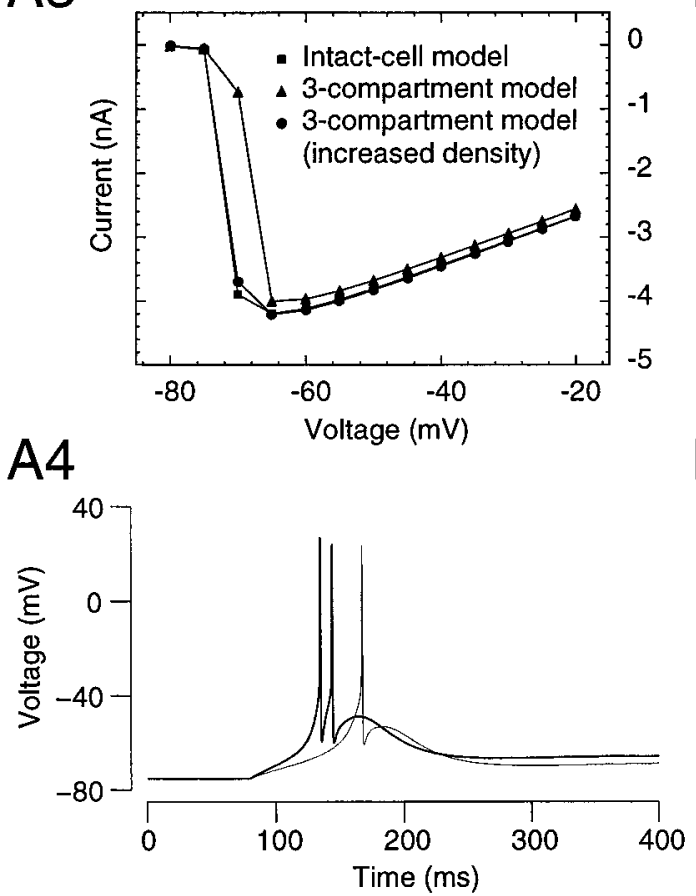

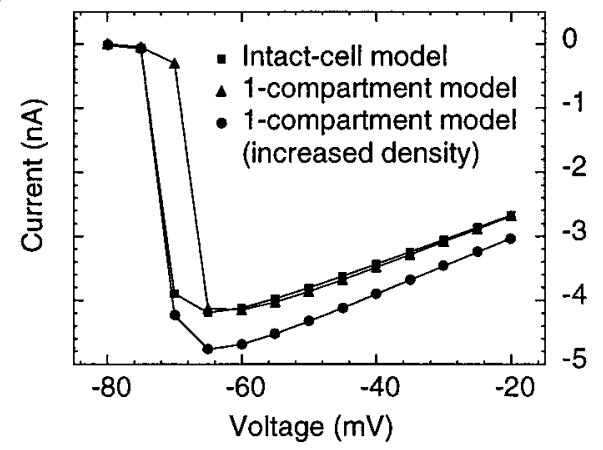

B4

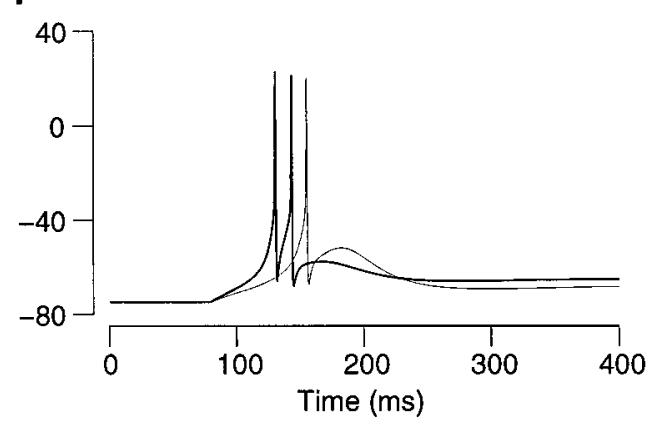

Figure 11. Simplified models of TC cells. A1, Three-compartment model obtained by collapsing the dendritic morphology of the intact cell (see Materials and Methods). A2, Adjustment of the dendritic correction of the model to obtain passive properties consistent with experimental recordings. $A 3, I-V$ curves in voltage clamp, comparing the intact-cell model (squares) with the simplified model with the same density of T-current (triangles; same densities as in Fig. $9 C$ ). A slightly increased dendritic density matched the $I-V$ curve of the intact model (circles; dendritic density of $9.5 \times 10^{-5} \mathrm{~cm} / \mathrm{sec}$ ). $A 4$, Low-threshold bursts with the simplified model $\left(9.5 \times 10^{-5} \mathrm{~cm} / \mathrm{sec}\right) . B 1$, Single-compartment model of the TC cell. B2, Adjustment of the membrane area such that the model fits experimental passive responses. $B 3, I-V$ curves in voltage clamp, with intact-cell model (squares) and its best match with the single-compartment model (triangles; density of $6 \times 10^{-5} \mathrm{~cm} / \mathrm{sec}$ ). The circles indicate the model needed to reproduce current-clamp behavior (density of $8 \times 10^{-5} \mathrm{~cm} / \mathrm{sec}$ ). B4, Low-threshold bursts with the single-compartment model (density of $8 \times 10^{-5} \mathrm{~cm} / \mathrm{sec}$ ).

detailed model, the total membrane area was adjusted by fitting the one-compartment model until it matched the passive responses of the TC cells under voltage clamp (Fig. 11B2).

The density of T-current was calculated such that the total amount of T-channels was identical to the detailed model. In this case, the peak amplitude of the T-current was similar to the detailed model, but the $I-V$ curves were different (Fig. 11B3, compare triangles, squares). Contrary to the three-compartment model, it was not possible to match these $I-V$ curves. In these conditions, the model did not generate low-threshold burst responses consistent with experimental data (data not shown). However, if the T-current density was increased, such that the 
Figure 12. Burst responses in the threecompartment model of TC cells with dendritic T-current. $A$, Current-clamp simulations of LTS generation in the three-compartment TC cell model using two different amplitudes of injected depolarizing current (50 and $75 \mathrm{pA}$ from rest; Fig. $9 B, C) . A 1$, No LTS could be generated with uniform T-current density based on dissociated cell recordings $\left(1.7 \times 10^{-5} \mathrm{~cm} / \mathrm{sec}\right.$, indicated by gray shades in the scheme). A2, Successful LTS generation in the simplified model with high densities of T-current in dendrites $\left(9.5 \times 10^{-5}\right.$ $\mathrm{cm} / \mathrm{sec}$, indicated by black shades in the scheme). $B$, LTS peak amplitude represented as a function of the amplitude of injected current in the soma (similar description as in Fig. 10). Somatodendritic T-current distributions were Somatic \& dendritic (density of $1.7 \times 10^{-5} \mathrm{~cm} /$ sec perisomatic and $9.5 \times 10^{-5} \mathrm{~cm} / \mathrm{sec}$ dendritic) and Somatic only (density of $56.36 \times$ $10^{-5} \mathrm{~cm} / \mathrm{sec}$ exclusively in the soma). Burst responses and the differences attributable to channel segregation in the cell were similar to those of the reconstructed TC cell model (Fig. $10 B)$. $C$, LTS peak amplitudes in the presence of dendritic shunt conductances $\left(g_{\mathrm{L}}=0.15 \mathrm{mS} /\right.$ $\mathrm{cm}^{2}$ ). The enhanced differences between the two curves are comparable to those of the reconstructed TC cell model (Fig. 10C).
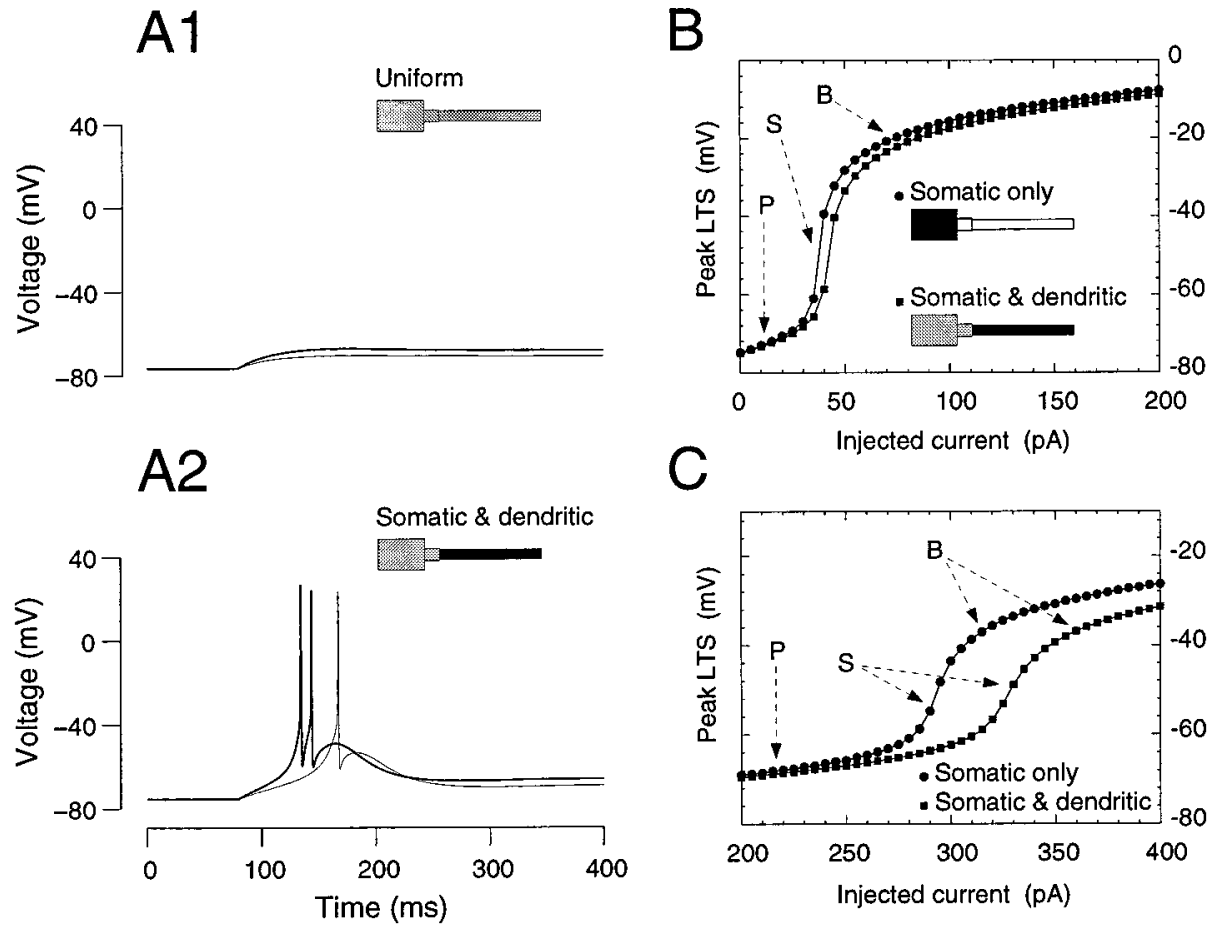

shape of the $I-V$ curve was similar to the detailed model (Fig. 11B3, compare circles, squares), then the single-compartment model could generate low-threshold burst responses consistent with experiments (Fig. 11B4).

This single-compartment model is of course too simple to account for data from intact and dissociated TC cells in the same time, but it still generates LTS consistent with intact TC cells in current clamp. Single-compartment models would therefore be more appropriate for building network simulations in which the central aim is to reproduce the rebound burst of TC cells (for example, see Destexhe et al., 1996a, 1998). Compared with the reconstructed cell model, the three-compartment model is $\sim 66$ times faster to simulate; therefore this type of model should be useful to simulate the electrophysiological behavior of single TC cells with more computational efficiency.

\section{DISCUSSION}

Having obtained current-clamp and voltage-clamp data from the same cell in conjunction with computational models based on the same cellular geometry is a rare opportunity. We have here combined these in vitro and computational approaches to constrain as much as possible the presence of T-current in the dendrites of TC cells. Dendritic T-current was needed to reproduce three essential features: (1) T-current recordings from dissociated TC cells, (2) T-current recordings from intact TC cells, and (3) the low-threshold burst response in intact TC cells. Not only dendritic T-current was needed, which was not a surprising result in light of optical imaging evidence (Munsch et al., 1997; Zhou et al., 1997), but the density needed to reproduce electrophysiological data was $\sim 4.5-7.6$ times that of the somatic region. In the next sections, we discuss successively the rationale leading us to conclude that TC cells possess high densities of dendritic T-current, possible sources of errors of the procedures followed here, and possible physiological consequences of the unexpectedly high T-current density in the distal dendrites of TC cells.

\section{Dendritic T-current in TC cells}

Optical-imaging experiments have clearly demonstrated the presence of T-current in the dendrites of TC cells (Munsch et al., 1997; Zhou et al., 1997), but no estimate of density was possible. In the present paper, we have estimated the T-current density in the dendrites of TC cells by combining electrophysiological measurements with computational models, with the following constraints. (1) The peak amplitude of T-current in dissociated TC cells was $\sim 400 \mathrm{pA}$. Because these cells have lost most of the dendritic tree, matching a dissociated cell model to those recordings provides estimates of the perisomatic density of T-current. (2) We show here that the peak T-current amplitude in intact TC cells is fairly large (2-8.3 nA), and simulations of a reconstructed TC cell show that not only the T-current must be present in dendrites, but its dendritic density must be increased several times to reproduce these experimental measurements. (3) $I-V$ curves of intact TC cells under voltage clamp are significantly shifted compared with that of dissociated TC cells. This phenomenon could be replicated based on a poor voltage control over dendritic T-channels. (4) The current-clamp behavior of the reconstructed TC cell was compared with the traces obtained in that cell during its recording. This turned out to be the most constraining data, because burst behavior needed a more narrow range of T-current densities in dendrites, 4.5-7.6 times higher than in the soma. (5) Similar conclusions were reached using a simplified model with only two dendritic compartments, provided that the most distal compartment had high densities of T-channels.

Our recordings and models therefore point to the conclusion that TC cells have somatodendritic distribution of $\mathrm{T}$ channels with most channels concentrated in distal portions of the dendrites ( $>11 \mu \mathrm{m}$ from soma), similar to the conclusions reached for thalamic RE cells (Destexhe et al., 1996b) and hippocampal pyramidal cells (Karst et al., 1993). 


\section{Possible errors in constraining the density of dendritic T-current}

First, one basic assumption was that the somatic density was accurately given by studying dissociated cells. There could be destruction of a significant portion of T-channels during the dissociation procedure, which would affect the present results. However, the fact that the T-current has a relatively constant amplitude among different dissociated TC cells indicates a relative integrity of the pool of T-channels in that preparation. Moreover, the same approach was used successfully to estimate the somatic and dendritic T-current densities in a previous study on thalamic reticular cells (Destexhe et al., 1996b). In that case, the estimated T-current densities reproduced typical electrophysiological features of RE cells, which is consistent with a low $\mathrm{T}$-current density in the proximal region.

Second, TC cells are characterized by many other intrinsic membrane currents (McCormick and Huguenard, 1992), which were not included here. In particular, the hyperpolarizationactivated inward current $\left(I_{\mathrm{h}}\right)$ is active at rest and may significantly influence the procedure followed here. However, simulations in the presence of $I_{\mathrm{h}}$ suggest that the same conclusions about the T-current density still hold (data not shown). There is no tight constraint for the density of $I_{\mathrm{h}}$ in intact TC cells of that age. When these constraints will become available, an adjustment of this model may be needed.

Third, the cell studied may not be representative of adult TC cells. The voltage-clamp recordings of intact TC cells were obtained from young rats (P12), and so was the reconstructed cell (P10). Therefore, the conclusions drawn here are valid for TC cells of that age, and further studies would be needed to characterize adult TC cells. However, TC cells of P10-P12 have already reached an advanced developmental state for low-threshold spike genesis (Perez Velazquez and Carlen, 1996; Pirchio et al., 1997; Warren and Jones, 1997), which suggests that the characteristics found here are also valid for adult TC cells. Moreover, the fact that the dendritic branches of TC cells are longer in adults compared with young animals (Warren and Jones, 1997) indicates that adult cells are electrotonically less compact, and that the effect of dendritic $I_{\mathrm{T}}$ may be even more pronounced than that suggested here.

\section{Possible functional consequences of dendritic T-current in TC cells}

The first possible consequence of dendritic T-current in TC cells is that it is likely to enhance the burst response in rebound to IPSPs. The dendrites of TC cells are densely covered by inhibitory synaptic terminals from RE cells (Jones, 1985), which evoke very powerful IPSPs that can trigger rebound bursts (Steriade and Deschênes, 1984; Bal et al., 1995a,b). A high density of T-current in the very same site as these terminals seems therefore optimal to facilitate the genesis of bursts in rebound to dendritic IPSPs. On the other hand, RE cells receive excitatory synaptic contacts from TC cells and have a more hyperpolarized resting state, at which the T-current is deinactivated (Contreras et al., 1993; Bal et al., 1995b; Destexhe et al., 1996b). Because they may also have dendritic T-current, RE cells seem optimally designed to produce bursts in response to EPSPs. Taken together, these data suggest that the interconnected TC-RE structure with dendritic T-currents makes a very efficient and robust oscillator, in which cells very powerfully elicit bursts in each other.

A second possible consequence is that cortical synapses may also interact with burst genesis and play a modulatory role. This type of interaction was already shown in a previous modeling study on thalamic RE cells (Destexhe et al., 1996b); the dendrites of RE cells are characterized by a high density of excitatory synapses of cortical origin (Jones, 1985). Therefore, the increase of background activity of excitatory synapses may counteract the genesis of the rebound burst if the T-channels are dendritic, because synaptic currents would act directly on T-channels at their precise site of localization, through shunting and depolarization. These types of local dendritic interactions were simulated by the model and had the consequence that moderate levels of excitatory synaptic activity interacted with burst genesis in the dendrites, leading to firing properties consistent with in vivo recordings (Destexhe et al., 1996b).

The present results suggest that similar interactions may also take place in the dendrites of TC cells: the evidence for high dendritic densities of T-current must be paralleled with morphological evidence showing that the dendrites of TC cells receive a considerable amount of corticothalamic synaptic terminals (Liu et al., 1995; Erisir et al., 1997), which are more numerous than terminals from sensory afferents (Jones, 1985). In addition, the dendrites of TC cell are also densely covered by inhibitory synapses (Jones, 1985; Liu et al., 1995). The model suggests that the T-current can be modulated more effectively when it is distributed in dendrites (Fig. 10), leading to a finer and more graded control of bursts. We propose that a possible reason to explain the presence of most of the T-channels in dendrites is a fine tuning of bursts by synaptic currents, through shunting mechanisms. This type of dendritic interactions could provide a very fast switch between the burst mode (cortical synapses silent) and the tonic mode (sustained cortical drive). In addition to conventional neuromodulatory mechanisms, which operate over time scales of hundreds of milliseconds (McCormick, 1992), these types of local dendritic interactions give to corticothalamic feedback the potentiality to control the state of thalamic neurons within a few milliseconds. Experimental measurement of the amount of synaptic conductance activated by corticothalamic feedback in the dendrites of TC cells would be needed to test this hypothesis further.

\section{REFERENCES}

Andersen P, Eccles JC (1962) Inhibitory phasing of neuronal discharge. Nature 196:645-647.

Andersen P, Rutjord T (1964) Simulation of a neuronal network operating rhythmically through recurrent inhibition. Nature 204:289-190.

Bal T, von Krosigk M, McCormick DA (1995a) Synaptic and membrane mechanisms underlying synchronized oscillations in the ferret LGNd in vitro. J Physiol (Lond) 483:641-663.

Bal T, von Krosigk M, McCormick DA (1995b) Role of the ferret perigeniculate nucleus in the generation of synchronized oscillations in vitro. J Physiol (Lond) 483:665-685.

Bloomfield SA, Hamos JE, Sherman SM (1987) Passive cable properties and morphological correlates of neurones in the lateral geniculate nucleus of the cat. J Physiol (Lond) 383:653-692.

Bush PC, Sejnowski TJ (1993) Reduced compartmental models of neocortical pyramidal cells. J Neurosci Methods 46:159-166.

Contreras D, Curró Dossi R, Steriade M (1993) Electrophysiological properties of cat reticular thalamic neurones in vivo. J Physiol (Lond) 470:273-294.

Coulter DA, Huguenard JR, Prince DA (1989) Calcium currents in rat thalamocortical relay neurones: kinetic properties of the transient, low-threshold current. J Physiol (Lond) 414:587-604.

Crunelli V, Leresche N, Paravelas J (1987) Membrane properties of morphologically identified $\mathrm{X}$ and $\mathrm{Y}$ cells in the lateral geniculate nucleus of the cat in vitro. J Physiol (Lond) 390:243-256.

Deschênes M, Paradis M, Roy JP, Steriade M (1984) Electrophysiology of neurons of lateral thalamic nuclei in cat: resting properties and burst discharges. J Neurophysiol 55:1196-1219. 
Destexhe A, Sejnowski TJ (1997) Synchronized oscillations in thalamic networks: insights from modeling studies. In: Thalamus (Steriade M, Jones EG, McCormick DA, ed), pp 331-371. Amsterdam: Elsevier.

Destexhe A, McCormick DA, Sejnowski TJ (1993) A model for 8-10 Hz spindling in interconnected thalamic relay and reticularis neurons. Biophys J 65:2474-2478.

Destexhe A, Bal T, McCormick DA, Sejnowski TJ (1996a) Ionic mechanisms underlying synchronized oscillations and propagating waves in a model of ferret thalamic slices. J Neurophysiol 76:2049-2070.

Destexhe A, Contreras D, Steriade M, Sejnowski TJ, Huguenard JR (1996b) In vivo, in vitro and computational analysis of dendritic calcium currents in thalamic reticular neurons. J Neurosci 16:169-185.

Destexhe A, Contreras D, Steriade M (1998) Mechanisms underlying the synchronizing action of corticothalamic feedback through inhibition of thalamic relay cells. J Neurophysiol 79:999-1016.

Erisir A, VanHorn SC, Bickford ME, Sherman SM (1997) Immunocytochemistry and distribution of parabrachial terminals in the lateral geniculate nucleus of the cat: a comparison with corticogeniculate terminals. J Comp Neurol 377:535-549.

Golomb D, Wang XJ, Rinzel J (1996) Propagation of spindle waves in a thalamic slice model. J Neurophysiol 75:750-769.

Hille B (1992) Ionic channels of excitable membranes. Sunderland, MA: Sinauer.

Hines ML, Carnevale NT (1997) The NEURON simulation environment. Neural Comput 9:1179-1209.

Hodgkin AL, Huxley AF (1952) A quantitative description of membrane current and its application to conduction and excitation in nerve. J Physiol (Lond) 117:500-544.

Huguenard JR (1998) Heterogeneity of LVA calcium currents in thalamic neurons and their functional role in burst firing. In: Low voltage activated T-type calcium channels (Tsien RW, Nargeot J, ed), pp 143-152. Chester, UK: Adis International.

Huguenard JR, McCormick DA (1992) Simulation of the currents involved in rhythmic oscillations in thalamic relay neurons. J Neurophysiol 68:1373-1383.

Huguenard JR, Prince DA (1992) A novel T-type current underlies prolonged $\mathrm{Ca}^{2+}$-dependent bursts firing in GABAergic neurons of rat thalamic reticular nucleus. J Neurosci 12:3804-3817.

Huguenard JR, Hamill OP, Prince DA (1988) Developmental changes in $\mathrm{Na}^{+}$conductances in rat neocortical neurons: appearance of a slowly inactivating component. J Neurophysiol 59:778-795.

Karst H, Joels M, Wadman WJ (1993) Low-threshold calcium current in dendrites of the adult rat hippocampus. Neurosci Lett 164:154-158.

Jahnsen H, Llinás RR (1984a) Electrophysiological properties of guinea-pig thalamic neurons: an in vitro study. J Physiol (Lond) 349:205-226.

Jahnsen H, Llinás RR (1984b) Ionic basis for the electroresponsiveness and oscillatory properties of guinea-pig thalamic neurons in vitro. J Physiol (Lond) 349:227-247.

Jones EG (1985) The thalamus. New York: Plenum.

Liu XB, Honda CN, Jones EG (1995) Distribution of four types of synapse on physiologically identified relay neurons in the ventral posterior thalamic nucleus of the cat. J Comp Neurol 352:69-91.

Magee JC, Johnston D (1995) Characterization of single voltage-gated $\mathrm{Na}^{+}$and $\mathrm{Ca}^{2+}$ channels in apical dendrites of rat CA1 pyramidal neurons. J Physiol (Lond) 487:67-90.
McCormick DA (1992) Neurotransmitter actions in the thalamus and cerebral cortex and their role in neuromodulation of thalamocortical activity. Prog Neurobiol 39:337-388.

McCormick DA, Huguenard JR (1992) A model of the electrophysiological properties of thalamocortical relay neurons. J Neurophysiol 68:1384-1400.

Müller W, Lux HD (1993) Analysis of voltage-dependent membrane currents in spatially extended neurons from point-clamp data. J Neurophysiol 69:241-247.

Munsch T, Budde T, Pape HC (1997) Voltage-activated intracellular calcium transients in thalamic relay cells and interneurons. NeuroReport 11:2411-2418.

Neubig M, Destexhe A (1997) Construction of low-order computational models which accommodate spatial distributions of afferent synapses received by thalamocortical neurons. Soc Neurosci Abstr 23:573.

Ohara PT, Havton LA (1994) Dendritic architecture of rat somatosensory thalamocortical projection neurons. J Comp Neurol 341:159-171.

Pape HC (1996) Queer current and pacemaker: the hyperpolarizationactivated cation current in neurons. Ann Rev Physiol 58:299-327.

Perez Velazquez JL, Carlen PL (1996) Development of firing patterns and electrical properties in neurons of the rat ventrobasal thalamus. Dev Brain Res 91:164-170.

Pirchio M, Turner JP, Williams SR, Asprodini E, Crunelli V (1997) Postnatal development of membrane properties and delta oscillations in thalamocortical neurons of the cat dorsal lateral geniculate nucleus. J Neurosci 17:5428-5444.

Press WH, Flannery BP, Teukolsky SA, Vetterling WT (1986) Numerical recipes. The art of scientific computing. Cambridge, UK: Cambridge UP.

Rall W, Burke RE, Holmes WR, Jack JJ, Redman SJ, Segev I (1992) Matching dendritic neuron models to experimental data. Physiol Rev 72:S159-S186.

Steriade M, Deschênes M (1984) The thalamus as a neuronal oscillator. Brain Res Rev 8:1-63.

Steriade M, Deschênes M, Domich L, Mulle C (1985) Abolition of spindle oscillations in thalamic neurons disconnected from nucleus reticularis thalami. J Neurophysiol 54:1473-1497.

Steriade M, Jones EG, Llinás RR (1990) Thalamic oscillations and signalling. New York: Wiley.

Traub RD, Miles R (1991) Neuronal networks of the hippocampus. Cambridge, UK: Cambridge UP.

Ulrich D, Huguenard JR (1995) Purinergic inhibition of GABA and glutamate release in the thalamus: implications for thalamic network activity. Neuron 15:909-918.

von Krosigk M, Bal T, McCormick, DA (1993) Cellular mechanisms of a synchronized oscillation in the thalamus. Science 261:361-364.

Wang XJ, Golomb D, Rinzel J (1995) Emergent spindle oscillations and intermittent burst firing in a thalamic model: specific neuronal mechanisms. Proc Natl Acad Sci USA 92:5577-5581.

Warren RA, Jones EG (1997) Maturation of neuronal form and function in a mouse thalamo-cortical circuit. J Neurosci 17:277-295.

Zhou Q, Godwin DW, O'Malley DM, Adams PR (1997) Visualisation of calcium influx through channels that shape the burst and tonic firing modes of thalamic relay cells. J Neurophysiol 77:2816-2825. 